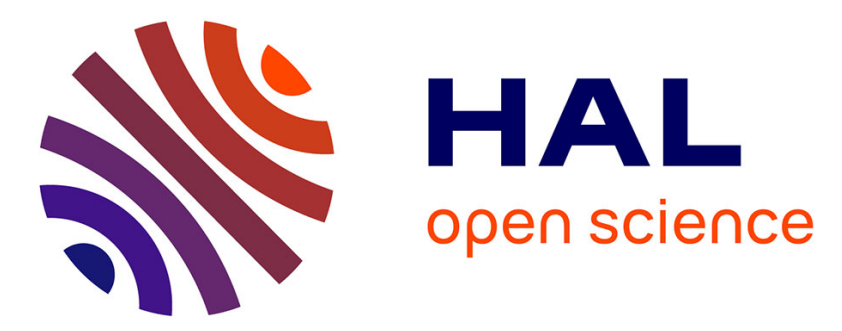

\title{
Extensive sphingolipid depletion does not affect lipid raft integrity or lipid raft localization and efflux function of the ABC transporter MRP1
}

Karin Klappe, Anne-Jan Dijkhuis, Ina Hummel, Annie van Dam, Pavlina T Ivanova, Stephen B Milne, David S Myers, H Alex Brown, Hjalmar Permentier, Jan W Kok

\section{To cite this version:}

Karin Klappe, Anne-Jan Dijkhuis, Ina Hummel, Annie van Dam, Pavlina T Ivanova, et al.. Extensive sphingolipid depletion does not affect lipid raft integrity or lipid raft localization and efflux function of the ABC transporter MRP1. Biochemical Journal, 2010, 430 (3), pp.519-529. 10.1042/BJ20091882 . hal-00512004

\section{HAL Id: hal-00512004 https://hal.science/hal-00512004}

Submitted on 27 Aug 2010

HAL is a multi-disciplinary open access archive for the deposit and dissemination of scientific research documents, whether they are published or not. The documents may come from teaching and research institutions in France or abroad, or from public or private research centers.
L'archive ouverte pluridisciplinaire HAL, est destinée au dépôt et à la diffusion de documents scientifiques de niveau recherche, publiés ou non, émanant des établissements d'enseignement et de recherche français ou étrangers, des laboratoires publics ou privés. 


\title{
Extensive sphingolipid depletion does not affect lipid raft integrity or lipid raft localization and efflux function of the ABC transporter MRP1
}

\author{
Karin Klappe*, Anne-Jan Dijkhuis", Ina Hummel*, Annie van Dam ${ }^{\dagger}$, Pavlina T \\ Ivanova $^{\ddagger}$, Stephen B Milne ${ }^{\ddagger}$, David S Myers ${ }^{\ddagger}$, H Alex Brown ${ }^{\ddagger}$, Hjalmar Permentier ${ }^{\dagger}$, and \\ Jan W Kok*
}

*Department of Cell Biology, Section Membrane Cell Biology, University Medical Center Groningen, A. Deusinglaan 1, 9713 AV Groningen, The Netherlands, ${ }^{\dagger}$ Mass Spectometry Core Facility, University of Groningen, A. Deusinglaan 1, 9713 AV Groningen, The Netherlands, "Departments of Pharmacology and Chemistry, Vanderbilt University School of Medicine, 23rd Ave. S. at Pierce, Nashville, Tennessee, U.S.A.

Running Title: lipid rafts and MRP $1^{\S}$ function at low sphingolipid levels

\begin{abstract}
${ }^{\S}$ Abbreviations: ABC, ATP-binding cassette; Cav-1, caveolin-1; Cer, ceramide; CFDA, carboxyfluorescein diacetate; DRM, detergent-resistant membrane; ECL, enhanced chemiluminescence; FCS, fetal calf serum; GlcCer, glucosylceramide; GCS, UDPglucose:ceramide glucosyltransferase (GlcCer synthase); HBSS, Hank's balanced salt solution; IR, infrared, HPTLC, high performance thin layer chromatography; LacCer, lactosylceramide; LC-MS, liquid chromatography mass spectrometry; LC-ESI-MS/MS, liquid chromatography-electrospray ionization tandem mass spectrometry; MDR, multidrug resistance; MRP1, multidrug resistance-related protein 1; MTT, 3-[4,5-dimethylthiazol-2-yl]2,5-diphenyl tetrazolium bromide; PBS, phosphate buffered saline; PA, phosphatidic acid; PC, phosphatidylcholine, PE, phosphatidylethanolamine; PG, phosphatidylglycerol; PI, phosphatidylinositol; PS, phosphatidylserine; Pgp, P-glycoprotein; PNS, post nuclear supernatant; RT, room temperature; si, small interfering; SM, sphingomyelin; SPT, serine palmitoyltransferase; LC(B), long chain base subunit.
\end{abstract}

Correspondence to: Jan Willem Kok, University Medical Center Groningen, University of Groningen, Department of Cell Biology, Section Membrane Cell Biology, A. Deusinglaan 1, 9713 AV Groningen, The Netherlands, Tel. 31-50-3632725; Fax 31-50-3632728; E-mail: j.w.kok@med.umcg.nl 


\section{Synopsis}

We show that highly efficient depletion of sphingolipids in two different cell lines does not abrogate the ability to isolate lubrol-based detergent-resistant membranes $\left(\mathrm{DRMs}^{\S}\right)$ or detergent-free lipid rafts from these cells. Compared to control, DRM/detergent-free lipid raft fractions contain equal amounts of protein, cholesterol and phospholipid, while the classical DRM/lipid raft markers Src, caveolin-1 (Cav-1) and flotillin display the same gradient distribution. DRMs/detergent-free lipid rafts themselves are severely depleted of sphingolipids. The fatty acid profile of the remaining sphingolipids as well as that of the glycerophospholipids shows several differences compared to control, most prominently an increase of highly saturated C16 species. The glycerophospholipid headgroup composition is unchanged in sphingolipid depleted cells and cell-derived detergent-free lipid rafts.

Sphingolipid depletion does not alter the localization of multidrug resistance-related protein 1 (MRP1) in DRMs/detergent-free lipid rafts or MRP1-mediated efflux of carboxyfluorescein. We conclude that extensive sphingolipid depletion does not affect lipid raft integrity in two cell lines and does not affect the function of the lipid raft-associated protein MRP1.

Supplementary key words: detergent-free lipid rafts, Src, caveolin, flotillin, ISP-1, Neuro-2a, $\mathrm{BHK} / \mathrm{MRP} 1$ 


\section{Introduction}

Lipid rafts have been established as an important feature in cell membranes with regard to signal transduction, cell adhesion and protein sorting [1]. The physical properties of these membrane microdomains are distinct from those of the surrounding membrane. This is generally considered to be the result of a different lipid composition in these domains compared to the surrounding membrane. Membrane microdomains are enriched in cholesterol and sphingolipids with a high degree of saturation in their fatty acyl chains. The presence of these lipids is thought to stabilise membrane domains, due to the ability of saturated sphingolipids and cholesterol to tightly pack in the plane of the membrane [2,3]. In model membranes cholesterol induces tight packing of sphingolipids into a liquid-ordered $\left(l_{0}\right)$ state. It is not known how membrane microdomains arise in cells, but it is likely that this process is initiated by small scale protein-lipid interactions followed by domain size increase due to protein-protein interactions [4]. Lipid rafts in cells are operationally defined as complexes of molecules that are insoluble at low temperature in detergents, such as Lubrol and Triton X$100[5,6]$. We refer to these isolated lipid rafts as detergent-resistant membranes (DRMs). Most studies on the occurrence, properties and functions of lipid rafts in cells rely on the use of detergents for their isolation, but detergent-free isolation methods have also been developed [7]. We will use the term detergent-free lipid rafts exclusively for membrane domains isolated with the detergent-free isolation procedure. Finally, the term lipid raft per se will only be used to refer to the theoretical concept of membrane microdomains, according to the hypothesis based on a body of literature [8].

ATP-binding cassette (ABC) transporter proteins, such as P-glycoprotein (Pgp or $\mathrm{ABCB} 1$ ) and multidrug resistance-related protein 1 (MRP1 or ABCC1) have been associated with DRMs. Originally Pgp was localized in caveolae [9,10], but later studies showed localization of both Pgp and MRP1 in non-caveolar DRMs [11,12]. Both ABC transporters were more strongly enriched in Lubrol-based DRMs compared to Triton X-100-based DRMs [11]. Given their localization in DRMs, the function of ABC transporters may well be dependent on or modulated by sphingolipids and/or cholesterol. Indeed, some evidence exists for modulation of Pgp function by cholesterol and involvement of DRMs in this process $[13,14]$. Concerning a role for sphingolipids in modulation of $\mathrm{ABC}$ transporter function, several hypotheses exist but a coherent picture has not yet emerged. In multidrug resistant (MDR) cells overexpressing Pgp or MRP1, several changes in sphingolipid metabolism have been observed, including accumulation of glucosylceramide (GlcCer). The latter has been related to increased glucosylceramide synthase (GCS) activity [15]. Because GCS is responsible for metabolic removal of ceramide (Cer) from the sphingolipid pool, an increased activity of this enzyme is beneficial to tumour cells that are under stress of cytostatics or other stress factors that induce Cer formation and subsequent apoptosis. On the other hand, enhanced GlcCer formation may be part of a more comprehensive response involving upregulation of the total glycolipid pool, including gangliosides. The latter may be involved in MDR, either related to or independent of $A B C$ transporters [16]. One study described that gangliosides activate Pgp through modulation of its phosphorylation state [17]. Another study reached the conclusion that gangliosides are not involved in modulation of $\mathrm{ABC}$ transporter localization and function [18].

Most evidence for a role of lipid rafts in cell function is based on studies showing DRM association of proteins and modulation of function of such proteins by procedures aimed at removing or modifying membrane cholesterol, such as methyl- $\beta$-cyclodextrin treatment [19]. Only few studies (for example ref. [20]) have employed depletion of sphingolipids as a means to perturb lipid raft association of proteins, even though sphingolipids are widely recognized as important building blocks of lipid raft membranes. In this study we investigated the role of sphingolipids in the integrity of DRMs in two different 
cell lines and show that highly efficient depletion of these lipids from cells and DRMs does not abrogate the ability to isolate DRMs employing Lubrol. DRM integrity was confirmed by protein content and gradient distribution of the classical DRM markers Src, caveolin-1 (Cav1) and flotillin. In addition, detergent-free lipid rafts could be isolated from sphingolipiddepleted cells. Again, no effects on lipid raft integrity were observed upon sphingolipid depletion, as indicated by similar protein, cholesterol and phospholipid content and lipid raft marker distributions compared to lipid rafts from control cells. The fatty acid profile of the remaining sphingolipids as well as that of the glycerophospholipids showed several changes compared to control in whole cells and detergent-free lipid rafts, most prominently towards highly saturated, short-chain species.

Sphingolipid depletion did not affect MRP1 localization in DRMs/detergent-free lipid rafts or MRP1 efflux activity. We conclude that very low levels of sphingolipids are sufficient to sustain DRM/detergent-free lipid raft integrity as well as MRP1 localization in lipid rafts and its efflux activity. 


\section{Materials and methods}

\section{Materials}

MK571 was a gift from Prof. A.W. Ford-Hutchinson (Merck-Frosst, Inc., Kirkland, Canada). All cell culture plastic was from Corning, Inc. (Corning, NY). Cell culture media, Hank's balanced salt solution (HBSS), antibiotics, L-glutamine, sodium pyruvate and trypsin were from Gibco (Invitrogen, Paisley, UK). Fetal calf serum (FCS) was from Bodinco (Alkmaar, The Netherlands). L-[U- $\left.{ }^{14} \mathrm{C}\right]$ serine was purchased from Amersham Pharmacia Biotech UK Limited (Buckinghamshire, UK). High performance thin layer chromatography (HPTLC) plates were from Merck (Amsterdam, The Netherlands). C12-fatty acid homologues of Cer, sphingomyelin (SM), glucosylceramide (GlcCer) and lactosylceramide (LacCer) were from Avanti Polar Lipids (Alabaster, AL, USA). Gangliosides were purchased from Alexis Biochemicals (San Diego, CA, USA). 5-Carboxyfluorescein diacetate (CFDA) and 3-[4,5dimethylthiazol-2-yl]-2,5-diphenyl tetrazolium bromide (MTT) were from Sigma-Aldrich (St. Louis, MO, USA). Lubrol was obtained from Serva (Heidelberg, Germany). ISP-1 was from Biomol Research Laboratories Inc. (Plymouth Meeting, PA, USA). Lipofectamine ${ }^{\mathrm{TM}} 2000$ reagent, Silencer Select Pre-designed siRNA for serine palmitoyl transferase long chain base subunit 1 (SPTLC1) and SPTLC2 were purchased from Invitrogen (Paisley, UK). OptiPrep was from Axis-Shield PoC AS (Dundee, Scotland). The rat monoclonal anti-MRP1 (MRPr1) antibody was obtained from Signet Laboratories (Dedham, MD, USA). The polyclonal anticaveolin 1 (Cav-1) antibody and the monoclonal anti-flotillin antibodies were from Transduction Laboratories (Lexington, KY, USA). The polyclonal anti-c-Src antibody was from Santa Cruz Biotechnology Inc. (Santa Cruz, CA, USA). Purified mouse anti-long chain base subunit 1 (LCB1) was purchased from BD transduction laboratories (Franklin Lakes, NJ, USA). Serine palmitoyl transferase antibody (detecting LCB2) was from Abcam Inc. (Cambridge, MA, USA).

\section{Cell culture}

The murine neuroblastoma cell line Neuro-2a was purchased from the ATCC (Manassas, VA, USA). These cells were grown as adherent monolayer cultures in Dulbecco's modified Eagle medium supplemented with $10 \%$ FCS, 100 units $/ \mathrm{ml}$ penicillin, $100 \mu \mathrm{g} / \mathrm{ml}$ streptomycin, 2 mM L-glutamine and $1 \mathrm{mM}$ sodium pyruvate, under standard incubator conditions (humidified atmosphere, $5 \% \mathrm{CO}_{2}, 37^{\circ} \mathrm{C}$ ). The hamster BHK cell line stably expressing the human MRP1/ABCC1 gene, BHK/MRP1(ABCC1), was a gift from Dr. Riordan (Mayo Clinic Arizona, S.C. Johnson Medical Research Center, Scottsdale, AZ, USA; ref. [21]). These cells were grown as adherent monolayer cultures in Dulbecco's modified Eagle medium/NUT mix F-12 (1:1) supplemented with 10\% FCS, 100 units $/ \mathrm{ml}$ penicillin, $100 \mathrm{ug} / \mathrm{ml}$ streptomycin and $2 \mathrm{mM}$ L-glutamine, under standard incubator conditions (humidified atmosphere, $5 \% \mathrm{CO}_{2}$, $37^{\circ} \mathrm{C}$ ). The BHK/MRP1 cells were kept under selective pressure by growing them in the presence of $100 \mu \mathrm{M}$ methotrexate.

\section{Isolation of DRMs}

DRM fractions were isolated from cells as described [22]. For each isolation, confluent cells from two $75 \mathrm{~cm}^{2}$ flasks were washed once with TNE buffer ( $20 \mathrm{mM}$ Tris $\mathrm{HCl} \mathrm{pH} 7.4,150$ $\mathrm{mM} \mathrm{NaCl}, 1 \mathrm{mM}$ EDTA) and harvested by scraping in $2 \mathrm{ml}$ of ice-cold TNE buffer containing $0.5 \%(\mathrm{w} / \mathrm{v})$ Lubrol and protease inhibitors. After $30 \mathrm{~min}$ incubation on ice, cells were homogenized by passing the lysate twenty times through a 25 Gauge needle. Two $\mathrm{ml}$ of the lysate was transferred to a centrifuge tube and mixed with $2 \mathrm{ml}$ of $80 \%(\mathrm{w} / \mathrm{v})$ sucrose in TNE. On top of this, $4 \mathrm{ml}$ of $35 \%(\mathrm{w} / \mathrm{v})$ and $3 \mathrm{ml}$ of $5 \%(\mathrm{w} / \mathrm{v})$ sucrose in TNE were successively loaded, resulting in a discontinuous gradient. Gradients were centrifuged in a Beckman SW41 swing-out rotor (Beckman Coulter, Inc., Fullerton, CA, USA) at 40,000 rpm 
for $18-20 \mathrm{~h}$ at $4^{\circ} \mathrm{C}$. Eleven fractions of $1 \mathrm{ml}$ each were collected (from top to bottom), vortexed and stored at $-80^{\circ} \mathrm{C}$. The protein content [23] of all fractions was measured using bovine serum albumin as a standard.

\section{Isolation of detergent-free lipid rafts}

Detergent-free lipid rafts were isolated as described [7]. The whole procedure was performed on ice. In short, confluent cells of two $75 \mathrm{~cm}^{2}$ flasks were washed with base buffer $(20 \mathrm{mM}$ Tris- $\mathrm{HCl} \mathrm{pH} 7.8,250 \mathrm{mM}$ sucrose) supplemented with $1 \mathrm{mM} \mathrm{CaCl}_{2}$ and $1 \mathrm{mM} \mathrm{MgCl}_{2}$. The cells were collected by scraping in this solution and centrifuged for $2 \mathrm{~min}$ at $250 \mathrm{~g}$. The resulting pellet was suspended in $1 \mathrm{ml}$ of base buffer supplemented with $1 \mathrm{mM} \mathrm{CaCl}_{2}, 1 \mathrm{mM}$ $\mathrm{MgCl}_{2}$ and protease inhibitors. After homogenization by passage through a 25 Gauge needle 20 times, another centrifugation step for $10 \mathrm{~min}$ at $1000 \mathrm{~g}$ followed. The resulting post nuclear supernatant (PNS) was collected and transferred to a separate tube. The pellet was homogenized again in $1 \mathrm{ml}$ base buffer supplemented with $1 \mathrm{mM} \mathrm{CaCl}_{2}, 1 \mathrm{mM} \mathrm{MgCl}_{2}$ and protease inhibitors, sheered through the needle 20 times and centrifuged. The second PNS was combined with the first. Protein content of the combined PNS was determined [23] and samples were processed for gradient analysis based on equal amounts of protein, adjusted to 2 $\mathrm{ml}$ volumes. Subsequently, $2 \mathrm{ml}$ of base buffer containing 50\% OptiPrep was added to this 2 $\mathrm{ml}$ PNS. By using a gradient mixer, $8 \mathrm{ml}$ gradient of $0 \%$ to $20 \%$ OptiPrep in base buffer is poured on top of this $4 \mathrm{ml}$ in a centrifugation tube. After centrifugation for $90 \mathrm{~min}$ at 22,000 rpm and $4{ }^{\circ} \mathrm{C}$ in a Beckman SW41 rotor (Beckman Coulter, Inc., Fullerton, CA, USA) fractions of $1.34 \mathrm{ml}$ were collected (from top to bottom) and stored at $-80{ }^{\circ} \mathrm{C}$. The protein content [24] of all the fractions was measured using bovine serum albumin as a standard.

\section{Analysis of cholesterol and phospholipid content}

Lipids were extracted from detergent-free lipid raft fractions [25]. In the extract the cholesterol concentration was determined spectrophotometrically by a cholesterol oxidase/peroxidase assay [26]. The phosphorus content, as a measure for the phospholipid content in the fractions, was determined by a phosphate assay [27].

\section{Equilibrium radiolabeling and analysis of cellular sphingolipids}

Sphingolipid pools were metabolically radiolabeled by growing the cells for $72 \mathrm{~h}$ in the presence of $\mathrm{L}-\left[\mathrm{U}_{-}{ }^{14} \mathrm{C}\right]$ serine $(0.5 \mu \mathrm{Ci} / \mathrm{ml})$, a precursor molecule for sphingolipid biosynthesis. Cells were harvested by scraping and centrifuged, followed by lipid extraction from the cell pellet [25]. Aliquots of the lipid extracts were taken for determination of the total amount of lipid-incorporated radioactivity. Glycerolipids were hydrolyzed during a $1 \mathrm{~h}$ incubation at $37^{\circ} \mathrm{C}$ in $\mathrm{CHCl}_{3} / \mathrm{CH}_{3} \mathrm{OH}(1: 1$, v/v) containing $\mathrm{KOH}(0.1 \mathrm{M})$. The remaining lipids were reextracted and applied on HPTLC plates. Plates were developed in $\mathrm{CHCl}_{3} / \mathrm{CH}_{3} \mathrm{OH} / \mathrm{H}_{2} \mathrm{O}$ $(14: 6: 1, \mathrm{v} / \mathrm{v} / \mathrm{v})$ in the first dimension. Plates were then sprayed with $2.5 \% \mathrm{H}_{3} \mathrm{BO}_{3}(\mathrm{w} / \mathrm{v})$ in $\mathrm{CH}_{3} \mathrm{OH}$ and developed in $\mathrm{CHCl}_{3} / \mathrm{CH}_{3} \mathrm{OH} / 25 \%(\mathrm{w} / \mathrm{v}) \mathrm{NH}_{4} \mathrm{OH}(13: 7: 1, \mathrm{v} / \mathrm{v} / \mathrm{v})$ in the second dimension. After autoradiography, GlcCer, LacCer and SM containing spots were identified with the aid of standards and scraped from the plates. Plates were then developed in the second dimension, but now in reversed direction, in $\mathrm{CHCl}_{3} / \mathrm{CH}_{3} \mathrm{COOH}(9: 1, \mathrm{v} / \mathrm{v})$. Plates were dried and, after staining in $\mathrm{I}_{2}$ vapor, Cer containing spots were scraped. Radioactivity was measured by scintillation counting (Packard Topcount microplate scintillation counter, Meriden, CT). Levels of a specific lipid class were expressed as dps incorporated in that specific lipid class per $10^{3}$ dps of total lipid-incorporated radioactivity. 
Liquid chromatography-electrospray ionization tandem mass spectrometry

Details are provided in the Supplementary Material and Methods section at http://www.BiochemJ.org/bj/.

\section{Ganglioside analysis}

Gangliosides were isolated from $40 \times 10^{6}$ cells. Pelleted cells were extracted in $\mathrm{CHCl}_{3} / \mathrm{CH}_{3} \mathrm{OH}$ $(1: 1 ; \mathrm{v} / \mathrm{v})$ and $\mathrm{CHCl}_{3} / \mathrm{CH}_{3} \mathrm{OH}(2: 1 ; \mathrm{v} / \mathrm{v})$. The supernatants were pooled, dried $\left(\mathrm{N}_{2}\right)$ and lipids were redissolved and sonicated in $\mathrm{CHCl}_{3} / \mathrm{CH}_{3} \mathrm{OH}(1: 1 ; \mathrm{v} / \mathrm{v})$. After centrifugation and overnight storage at $-20^{\circ} \mathrm{C}$, the supernatants were collected, dried and their phospholipid content was determined [27]. Aliquots containing equal amounts of phospholipid were redissolved in diisopropylether/1-butanol $(3: 2 ; \mathrm{v} / \mathrm{v})$, and $17 \mathrm{mM} \mathrm{NaCl}$ was added. The aqueous phase was re-extracted with diisopropylether/1-butanol and subsequently lyophilized. Samples were dissolved in $\mathrm{CH}_{3} \mathrm{OH} / \mathrm{H}_{2} \mathrm{O}(1: 1 ; \mathrm{v} / \mathrm{v})$ and loaded onto pre-washed Sep-Pak $\mathrm{C} 18$ cartridges. After rinsing $\left(\mathrm{H}_{2} \mathrm{O}\right)$, gangliosides were eluted with $\mathrm{CH}_{3} \mathrm{OH}$ and $\mathrm{CHCl}_{3} / \mathrm{CH}_{3} \mathrm{OH}$ $(1: 1 ; \mathrm{v} / \mathrm{v})$. The eluate was concentrated and loaded onto HPTLC plates, which were developed in $\mathrm{CHCl}_{3} / \mathrm{CH}_{3} \mathrm{OH} / 0.2 \%(\mathrm{w} / \mathrm{v}) \mathrm{CaCl}_{2}(11: 9: 2 ; \mathrm{v} / \mathrm{v} / \mathrm{v})$ and stained with Ehrlich reagent. Ganglioside band intensities were quantified using Scion Image Beta 4.0.2 (Scion Corporation, Frederick, MD) software and compared to a standard curve of GM3, ranging from 10 pmols to 5 nmols. In some experiments, gangliosides were metabolically radiolabeled by growing the cells for $72 \mathrm{~h}$ in the presence of L-[U- $\left.{ }^{14} \mathrm{C}\right]$ serine $(1.0 \mu \mathrm{Ci} / \mathrm{ml})$. After autoradiography, ganglioside containing spots were identified with the aid of standards and scraped from the plates. Radioactivity was measured by scintillation counting (Packard Topcount microplate scintillation counter, Meriden, CT).

\section{Immunoblot analysis}

In the case of equal protein loading, an equal amount of protein from each gradient fraction was trichloroacetic acid-precipitated and resuspended in sample buffer (5\% SDS, 5\% $\beta$ mercaptoethanol, $0.125 \mathrm{M}$ Tris-HCL pH 6.8, 40\% glycerol). In the case of equal volume loading, protein from equal volume samples of each gradient fraction was trichloroacetic acidprecipitated and resuspended in sample buffer. The samples were resolved on SDS-PAGE $(10 \%)$ minigels and subsequently electro transferred onto a nitrocellulose membrane (TransBlot Transfer Medium membrane, Bio-Rad, Hercules, CA, USA). The membranes were rinsed with phosphate buffered saline (PBS: $\mathrm{NaCl}, 137 \mathrm{mM}$; KCl, $2.7 \mathrm{mM} ; \mathrm{Na}_{2} \mathrm{HPO}_{4}, 10$ $\left.\mathrm{mM} ; \mathrm{KH}_{2} \mathrm{PO}_{4}, 1.76 \mathrm{mM} ; \mathrm{pH} 7.4\right)$ and incubated (1 h, room temperature (RT)) with Odyssey blocking buffer/PBS $(1: 1, \mathrm{v} / \mathrm{v})$. Membranes were incubated (overnight, $\left.4{ }^{\circ} \mathrm{C}\right)$ with a primary antibody against MRP1 (1:1000), Src (1:1000), Cav-1 (1:1000), or flotillin (1:1000) in Odyssey blocking buffer/PBS/0.1\% (v/v) Tween 20. Membranes were rinsed in washing buffer (PBS containing 0.1\% (v/v) Tween 20) and subsequently incubated for $1 \mathrm{~h}$ with the appropriate infrared (IR) dye-conjugated secondary antibody (1:5000) (LI-COR, Westburg, Leusden, The Netherlands) in Odyssey blocking buffer/PBS/0.1\% (v/v) Tween 20. After rinsing with washing buffer followed by PBS, the immunoblots were scanned with the Odyssey (LI-COR, Westburg, Leusden, The Netherlands) to visualize the immunoreactive complexes, according to the manufacturer's instructions. Relative quantification of the complexes was performed using the Odyssey software. In some cases, membranes were rinsed with PBS and incubated (1-2 h, RT) with $5 \%(\mathrm{w} / \mathrm{v})$ non-fat dry milk in PBS.

Membranes were rinsed in washing buffer (PBS containing $0.1 \%(\mathrm{v} / \mathrm{v})$ Tween 20$)$ and incubated (at least $2 \mathrm{~h}, \mathrm{RT}$ ) with a primary antibody against MRP1 (1:500), Src (1:1000), Cav-1 (1:1000) or flotillin (1:1000) in washing buffer containg $0.5 \%(\mathrm{w} / \mathrm{v})$ non-fat dry milk. Membranes were rinsed in washing buffer and subsequently incubated for $2 \mathrm{~h}$ with the appropriate horseradish peroxidase-conjugated secondary antibody (1:2000) (Amersham 
Biosciences, Buckinghamshire, UK) in washing buffer containing $0.5 \%(\mathrm{w} / \mathrm{v})$ non-fat dry milk (2 h, RT). Membranes were incubated in chemiluminescence substrate solution (enhanced chemiluminescence (ECL), Amersham Biosciences), according to the manufacturer's instructions, and immunoreactive complexes were visualized by exposure to a Konica Minolta medical film (Tokyo, Japan) and quantified using Scion Image Beta 4.0.2 (Scion Corporation, Frederick, MD) software.

Detection of MRP1-mediated efflux by flow cytometric analysis Cells were harvested by trypsinization, washed with HBSS and incubated with the MRP1 substrate 5-carboxyfluorescein diacetate (CFDA; $0.5 \mu \mathrm{M}$ in $\mathrm{HBSS}$ ) at $10^{\circ} \mathrm{C}$ for $60 \mathrm{~min}$. Cells were transferred to ice and washed with ice-cold HBSS. Subsequently, the cells were incubated at $37^{\circ} \mathrm{C}$ in the presence or absence of the MRP1 inhibitor MK571 (20 $\left.\mu \mathrm{M}\right)$ during various time intervals. All subsequent steps were performed on ice. The efflux of the fluorescent substrate was stopped by cold centrifugation and the cells were resuspended in ice-cold HBSS containing MK571. Retention of fluorescence was determined by flow cytometric analysis using an EliteTM flow cytometer (Beckman Coulter, Miami, FL). For each sample 5000 events were collected and analyzed using Win-list 5.0 software (Verity Software House Inc., Topsham, ME).

\section{RNAi of serine palmitoyl transferase}

Neuro-2a cells were plated at a density of 40,000 cells $/ \mathrm{ml}$. After $24 \mathrm{~h}$ cells were transfected with $6 \mathrm{nM}$ siRNA using $2 \mu \mathrm{g} / \mathrm{ml}$ LipofectamineTM 2000 Reagent according to the manufacturer's protocol. After $24 \mathrm{~h}$ the medium was refreshed and the cells were allowed to grow for another $24 \mathrm{~h}$. RNAi treatment was combined with ISP-1 treatment $(0.5 \mu \mathrm{M})$ during the entire incubation period.

\section{Measurement of cell viability (MTT assay)}

One thousand (Neuro-2a) or five thousand (BHK/MRP1) cells/well were plated in microtiter plates. For sphingolipid depletion, cells were incubated with ISP-1 $(0.5 \mu \mathrm{M})$ for three days, followed by determination of viable cells. In case of 7 days treatment, cells were preincubated with ISP-1 $(0.5 \mu \mathrm{M})$ for 4 days, subsequently trypsinized and plated in the presence of ISP-1. 3 days after plating viable cells were determined. Alternatively, during the last day of the 7 day treatment incubation with ISP-1 was performed in serum-free medium. The MTT assay was performed as previously described [28]. Briefly, $100 \mu \mathrm{g}$ MTT was added to each well and cells were incubated for $2 \mathrm{~h}$ at $37^{\circ} \mathrm{C}$. Plates were then centrifuged $(15 \mathrm{~min}, 900 \times \mathrm{g})$ and the supernatants were removed. Pellets were dissolved in DMSO and absorbance was measured in a microtiter plate reader ( $\mu$ Quant, Bio-Tek Instruments, Winooski, VT, USA) at a $\lambda$ of $570 \mathrm{~nm}$. The background absorbance was subtracted from all values and data were expressed as percentage compared to untreated control cells $(=100 \%)$. Alternatively, the MTT signal was expressed relative to protein content, as determined in a parallel set of cells. 


\section{Results}

\section{Efficient depletion of sphingolipid content}

The serine palmitoyl transferase inhibitor ISP-1 $(0.5 \mu \mathrm{M})$ efficiently depleted sphingolipid content in Neuro-2a cells upon a three-day incubation. The pool of sphingolipids was reduced by $88 \% \pm 5 \%(\mathrm{n}=3)$, as determined by equilibrium radiolabeling (Fig. 1A). Depletion was highly efficient for Cer and glycosphingolipids and slightly less for SM (Fig. 1A).

Measurement of endogenous sphingolipid mass using liquid chromatography-electrospray ionization tandem mass spectrometry showed similar results. Levels of Cer and glycosphingolipids were depleted by at least $90 \%$ in whole cells (Fig. 1B). SM depletion again was slightly less efficient (87\%). Importantly, when sphingolipids were analyzed in DRM fractions, also a highly efficient depletion by ISP-1 was observed, indicating that depletion was not confined to non-lipid raft membrane regions (Fig. 1C). Highly efficient depletion of sphingolipids by ISP-1 was also confirmed in detergent-free lipid raft fractions (Fig. 1D). In BHK/MRP1 cells similar results were obtained with ISP-1, although depletion was somewhat less efficient (Fig. 1E). In addition, we measured the level of gangliosides in Neuro-2a cells (Fig. 2). HPTLC analysis showed that GM3, the only ganglioside present in Neuro-2a cells, was undetectable in ISP-1-treated cells, indicating that ganglioside mass was very efficiently reduced by ISP-1-treatment. In BHK/MRP1 cells, gangliosides were undetectable in control cells, both by Ehrlich staining and by autoradiography after radiolabeling using $\mathrm{L}-\left[\mathrm{U}_{-}-{ }^{14} \mathrm{C}\right]$ serine. Using a standard curve of $\mathrm{GM} 3$, we estimated the amount of gangliosides in these cells to be less than 10 pmol per $10^{6}$ cells, which is less than $0.7 \%$ of the total sphingolipid pool. In Neuro-2a cells the amount of GM3 is 350 pmol per $10^{6}$ cells, which is $5.6 \%$ of the total sphingolipid pool.

The depletion of sphingolipids using ISP-1 did not significantly (unpaired t-test; P > 0.05 ) affect Neuro-2a cell viability, as determined by a MTT assay. Cell viability was $88.4 \%$ $\pm 16.8 \%(\mathrm{n}=6)$ for ISP-1-treated cells compared to control cells $(=100 \%)$.

\section{Depletion of sphingolipids does not abrogate Lubrol-based DRM isolation}

Surprisingly, when Neuro-2a cells were efficiently depleted of sphingolipids, we were still able to isolate Lubrol-based DRMs from these cells (Supplementary Figure S1 at http://www.BiochemJ.org/bj/). First of all, the protein content of these DRMs, i.e. the protein profile of the sucrose gradient fractions was identical to that of control cells (Supplementary Figure S1A at http://www.BiochemJ.org/bj/). Also the gradient distributions of established DRM protein markers Src, Cav-1 and flotillin were indistinguishable between ISP-1-treated and control cells (Fig. 3A). Indeed, quantification of these typical blots using the Odyssey protocol showed that the percentage of these lipid raft markers found to be associated with lipid rafts did not differ between control and ISP-1-treated cells (Fig. 3B). This was also the case in two other independent experiments, when quantification was performed using Scion Image software on protein bands stained with the ECL procedure (data not shown). Given these results, it was important to establish that sphingolipid depletion actually diminished the DRM-associated lipid pools. Alternatively, DRM-associated sphingolipids could have been spared upon treatment with ISP-1. However, as indicated above, results with isolated Lubrolbased DRMs (Fig. 1C) showed that Cer and glycosphingolipids were depleted by at least $90 \%$ and SM again somewhat less efficient (84\%). We conclude that efficient DRM depletion of sphingolipids did not hamper the potential to isolate DRMs from Neuro-2a cells.

Similar results were obtained when equal amounts of protein from all gradient fractions were processed for immunoblotting instead of equal volumes of gradient fractions. The difference is that with equal volume loading the final result reflects the distribution of the absolute amount of a given protein on a gradient, while with equal protein loading the result reflects the abundance of a given protein relative to total protein in a gradient fraction. The 
latter thus indicates the enrichment of a given protein in DRM fractions. Also with this procedure, raft association of the markers Src and Cav-1 was similar in control and ISP-1treated cells (Supplementary Figure S2A at http://www.BiochemJ.org/bj/).

Similar observations were made in BHK/MRP1 cells. Also in these cells, ISP-1 treatment did not abrogate the potential to isolate DRMs, based on gradient protein profile (Supplementary Figure S1B at http://www.BiochemJ.org/bj/) and gradient distribution of Src and Cav-1 (Supplementary Figure S2B at http://www.BiochemJ.org/bj/). Thus, these properties are not restricted to a single cell type.

\section{Depletion of sphingolipids does not abrogate detergent-free lipid raft isolation}

It is conceivable that the properties of DRMs as isolated by detergents, such as Lubrol, are strongly influenced by the use of detergent. Therefore, we additionally used a detergent-free method for the isolation of lipid rafts and tested the effect of sphingolipid depletion on integrity of these domains. We first characterized the gradient fractions in terms of cholesterol and sphingolipid enrichment. For this purpose, fractions $1 \& 2$ were pooled, as well as $3 \& 4$, $5 \& 6$ and 7-9. Fractions $1 \& 2$ were most strongly enriched in both cholesterol (Fig. 4A) and sphingolipids (Fig. 4B), and to a lesser extent also fractions $3 \& 4$. This indicates that fractions $1 \& 2$, with the lowest buoyant density, optimally fulfill the criteria for lipid rafts. Also with this detergent-free approach, lipid rafts could be isolated from sphingolipid-depleted Neuro-2a cells with protein profiles similar to control cells (Fig. 4C). In addition, the cholesterol profile (Fig. 4D) was unchanged in ISP-1-treated cells, as well as the phospholipid profile (Fig. 4E). The gradient distributions of the classical lipid raft markers Src, Cav-1 and flotillin were not changed upon treatment with ISP-1 (Fig. 5A). This was confirmed by quantification of the blots using the Odyssey protocol showing that the percentage of these lipid raft markers found to be associated with lipid rafts did not differ between control and ISP-1-treated cells (Fig. 5B). It is important to note that sphingolipid depletion by ISP-1 was equally effective in detergent-free lipid raft fractions as in whole cells (Fig. 1D). Also in BHK/MRP1 cells, the gradient distributions of Src and Cav-1 were not changed by ISP-1 (Fig. 5C), again indicating that the effect is not cell type specific

\section{Depletion of sphingolipids does not result in major changes in glycerophospholipid composition and cholesterol content in cells or detergent-free lipid rafts}

It is conceivable that the glycerophospholipid composition had changed in cells and/or lipid rafts with low sphingolipid levels after ISP-1 treatment as a compensation mechanism for the loss of sphingolipids. If this would be the case, we would expect to find increased levels of long, saturated fatty acids in glycerophospholipids, since these are considered to be enriched in lipid rafts. In addition, changes in headgroup composition of glycerophospholipids could have occurred. We employed LC-MS to analyze glycerophospholipids in terms of headgroup and fatty acid composition as well as total amount of glycerophospholipids. In whole Neuro2 a cells after $3 \mathrm{~d}$ of ISP-1 treatment there were no significant changes in the total glycerophospholipid content (Fig. 6A) or in the content of phosphatidic acid (PA), phosphatidylcholine (PC), phosphatidylethanolamine (PE), phosphatidylglycerol (PG), phosphatidylinositol (PI), phosphatidylserine (PS) (Fig. 6F). There were also no significant changes in the content of the lyso-forms of PE, PG and PI, or plasmalogens (data not shown). Concerning fatty acid composition of glycerophospholipids, minor changes were observed; Several relatively short-chain PAs, PCs, PEs and PIs were significantly reduced upon ISP-1 treatment (Supplementary Table SI at http://www.BiochemJ.org/bj/).

Next we analyzed the glycerophospholipid composition of detergent-free lipid rafts isolated from Neuro-2a cells. First, it became apparent that headgroup class composition of detergent-free lipid rafts was quite different from that of whole cells, detergent-free lipid rafts 
being enriched in PC and PS and relatively poor in PE and PG, while PA and PI were similar (Fig. 6G versus 6F). Relatively short-chain and saturated fatty acid species contributed most to the enrichment of PC and PS in detergent-free lipid rafts (data not shown). Second, the effect of ISP-1 on glycerophospholipid composition of detergent-free lipid rafts was confined to a significant decrease of several PA species, while the decrease in the total pool of PA was not significant, and a highly significant 38\% increase of PC(32:0) (Supplementary Table SI at http://www.BiochemJ.org/bj/). Similar to the situation in whole Neuro-2a cells, there were no significant changes in the total glycerophospholipid content of detergent-free lipid rafts isolated from Neuro-2a cells after 3d of ISP-1 treatment (Fig. 6B).

In BHK/MRP1 cells ISP-1 treatment did not result in significant changes in the total glycerophospholipid content (Fig. 6C) or in the content of PA, PC, PE, PG, PI, and PS (Fig. $6 \mathrm{H})$. Concerning fatty acid composition of glycerophospholipids, some changes were observed; Several PEs, PGs and more prominently PIs were significantly reduced upon ISP-1 treatment (Supplementary Table SI at http://www.BiochemJ.org/bj/). This concerned mostly longer chain fatty acid species.

The cholesterol content of Neuro-2a was not affected by ISP-1 treatment (Fig. 6D). The cholesterol content of Neuro-2a-derived detergent-free lipid rafts showed a trend of increase in ISP-1 treated cells, but this was not significant (Fig. 6E).

\section{Residual sphingolipids after ISP-1 treatment have a different fatty acid profile compared to control cells}

We also analyzed the fatty acid composition of the sphingolipids that remain after ISP-1 treatment. First, the fatty acid composition of sphingolipids in control Neuro-2a cells was relatively simple. In glycolipids about $90 \%$ was contributed by C16:0, C24:0 and C24:1 species. In SM, about 80\% were C16:0 species (Fig. 7). A comparable distribution was observed in BHK/MRP1 cells (data not shown). Second, ISP-1 treatment differentially affected fatty acid species in both Neuro-2a and BHK/MRP1 cells. Residual sphingolipids were relatively rich in short-chain species and relatively poor in C24:0 and C24:1 species (Table I). This pattern was to a certain extent reflected in Neuro-2a-derived detergent-free lipid rafts (Table I).

\section{Depletion of sphingolipids does not affect MRPI efflux activity or its localization in DRMs/detergent-free lipid rafts}

We next determined whether the DRM/lipid raft localization as well as the function of MRP1, a drug efflux pump active in both Neuro-2a and BHK/MRP1 cells, were affected by depletion of sphingolipids. This protein was chosen in view of its relevance to MDR, its association with Lubrol-based DRMs and the potential modulation of its activity by sphingolipids. To study its function, we tested MRP1-mediated carboxyfluorescein efflux activity. Untreated or ISP-1-treated Neuro-2a cells were loaded with CFDA. Efflux activity was determined on the basis of fluorescence retention after cells were incubated at $37^{\circ} \mathrm{C}$. The MRP1 inhibitor MK571 was used as a positive control for inhibition of MRP1-mediated efflux activity. MRP1 efflux activity was very similar in ISP-1-treated cells compared to control (Fig. 8A). Thus, depletion of sphingolipids using ISP-1 did not affect MRP1 efflux activity. In accordance, there was no effect on the DRM (Figs. 3A,B and Supplementary Figure S2A at http://www.BiochemJ.org/bj/) or detergent-free lipid raft (Fig. 5A,B) localization of the ABC transporter, as indicated by a very similar gradient distribution profile compared to that in control cells. Similarly, in BHK/MRP1 cells, the absence of an effect of ISP-1 on MRP-1mediated efflux (Fig. 8B) correlated with an unchanged gradient distribution of MRP1 (Supplementary Figure S2B at http://www.BiochemJ.org/bj/ and Fig. 5C). 
Combined ISP-1/SPT-RNAi treatment or long-term ISP-1 treatment does not further reduce sphingolipid levels

We have made several attempts to even further reduce the cellular sphingolipid levels. First, in Neuro-2a cells we combined ISP-1 treatment for 3 days with RNAi directed against SPTLC1 or SPTLC2 or both to downregulate the first enzyme in sphingolipid biosynthesis. Downregulation was effective as indicated by a residual levels of $67.3 \pm 26.0 \%(n=3)$ LCB1 for RNAi directed against SPTLC1 and $27.7 \pm 18.0 \%(n=3)$ LCB2 for RNAi directed against SPTLC2. Combined use of siRNA for SPTLC1 and SPTLC2 resulted in levels of $70.8 \pm 7.6$ $\%(\mathrm{n}=3)$ LCB1 and $42.7 \pm 11.4 \%(\mathrm{n}=3)$ LCB2 (Supplementary Figure S3 at $\mathrm{http}: / / \mathrm{www}$. BiochemJ.org/bj/). However, not any of these treatments combined with ISP-1 further reduced the level of sphingolipids as compared to ISP-1 treatment, but rather resulted in a higher residual levels (Supplementary Figure S4 at http://www.BiochemJ.org/bj/).

Second, we incubated Neuro-2a and BHK/MRP1 cells for 7 days in the presence of ISP-1. The final day of this treatment was performed in medium without serum, to prevent uptake of sphingolipids by the cells from the medium. Under these conditions we did not observe further reduction of the level of sphingolipids as compared to ISP-1 treatment during 3 days (Supplementary Figure S4 at http://www.BiochemJ.org/bj/). The viability of the cells started to be affected with this very long-term ISP-1 treatment (Supplementary Figure S5 at http://www.BiochemJ.org/bj/). Given that sphingolipids were not further reduced and sideeffects started to become apparent, we decided not to pursue further analysis of lipid rafts and MRP1 localization and function under these conditions. 


\section{Discussion}

Lipid rafts are subdomains of the plasma membrane that contain high concentrations of cholesterol and sphingolipids. They appear to be small in size, but together may constitute a relatively large fraction of the plasma membrane [29,30]. The high content of glycosphingolipids and SM in DRMs gave rise to two different models for lipid raft formation. The first model points out the importance of the relative long length and high saturation of the acyl chains of glycosphingolipids and SM for raft formation. This allows close packing of the lipids resulting in a high melting temperature $\left(\mathrm{T}_{\mathrm{m}}\right)$. Self-aggregates of sphingolipids form a separate phase that is less fluid (liquid-ordered) than the bulk liquiddisordered phospholipids. Cholesterol is recruited to these aggregates, due to its ability to pack tightly with lipids of high $\mathrm{T}_{\mathrm{m}}[2,3]$. According to the second model, lipid rafts are primarily clusters of glycosphingolipids and SM held together through hydrogen-bonding between glycosphingolipid head groups and close packing of the sphingolipids. Cholesterol fills up the gaps between the bulky-heads of the glycosphingolipids [30].

Interestingly, although glycosphingolipids are enriched in lipid rafts they do not appear to be essential for the formation of these membrane domains [31]. It was shown that glycosphingolipid-deficient GM95 melanoma cells had similar amounts of DRMs compared to control cells. The loss of glycosphingolipid mass in these cells due to mutation of the gene encoding GCS was exactly compensated by an increase in SM mass (van Riezen, M., Kok, J.W. and Merrill, A.H., jr., unpublished observations). Glycosphingolipids in DRMs of GM95 cells had been substituted by SM [31]. In this study we show for the first time that even under conditions when both glycosphingolipids and $\mathrm{SM}$, in fact when all sphingolipids are efficiently depleted from Neuro-2a cells during long-term (72 h) ISP-1 treatment, these cells still have similar amounts (protein content) of DRMs compared to control cells. In addition, three established lipid raft markers Src, cav-1 and flotillin were associated with lipid fractions to the same extent in control and ISP-1-treated cells. In this respect, it is important to note that our sphingolipid depletion procedure resulted not only in efficient reduction of the total cellular pools of these lipids, but was also highly effective in sphingolipid depletion from DRMs. This leads to the conclusion that DRMs can be isolated from cells which are severely depleted of sphingolipids. Thus, a minor amount of sphingolipids appears to be sufficient for the integrity of lipid rafts as defined by detergent-isolation. Moreover, formation of new lipid rafts seems to occur in cells with low levels of sphingolipid synthesis since new lipid raft formation is bound to occur during the long-term (72 h) ISP-1 treatment. We made several attempts to even further decrease sphingolipid levels below $10 \%$ of control (Neuro-2a cells). This was done by either combining pharmacological inhibition of SPT using ISP-1 with down-regulation of SPT using RNAi or by lengthening the incubation time with ISP-1 to 7 days, the last day carried out in combination with serum-free medium. Both procedures did not further reduce sphingolipid levels beyond those obtained after 3 days of ISP-1 incubation. Thus, depletion of sphingolipids to about $10 \%$ of control, as occurred in Neuro- $2 \mathrm{a}$ cells, appeared to be the maximum possible effect. For BHK/MRP1 cells, this was about $20 \%$ of control.

The use of detergents to isolate lipid rafts has been subject of extensive discussion and criticism [19,32-35]. It has been suggested that detergents induce artifacts, e.g. reorganization of molecules during the process of lipid raft isolation. Therefore, we additionally employed an established detergent-free method for lipid raft isolation [7]. We first characterized the gradients and showed that fractions $1 \& 2$ were highly enriched in cholesterol and sphingolipids, hallmarks of lipid rafts. As in the case of DRMs, also detergent-free lipid rafts could be readily isolated from cells after severe depletion of sphingolipids, as indicated by a similar protein profile in the gradients of control and ISP-1-treated cells. Moreover, also the gradient distributions of cholesterol and phospholipids were indistinguishable between control 
and ISP-1-treated cells. Finally, the classical lipid raft markers Src, Cav-1 and flotillin displayed similar association to lipid raft fractions in control and ISP-1-treated cells. Thus, in addition to DRMs, detergent-free lipid rafts can be readily isolated from sphingolipiddepleted cells and have very similar properties, except for the levels of sphingolipids. We have shown that these properties of DRMs and detergent-free lipid rafts are not confined to or specific for a single cell type, i.e. Neuro-2a cells. Similar results were obtained with a different cell type, i.e. BHK/MRP1 cells.

It is conceivable that the glycerophospholipid composition had changed in cells and/or lipid rafts with low sphingolipid levels after ISP-1 treatment as a compensation mechanism for the loss of sphingolipids. If this would be the case, we would expect to find increased levels of long, saturated fatty acids in glycerophospholipids, since lipids with these fatty acids are considered to be enriched in lipid rafts. In addition, changes in headgroup composition of glycerophospholipids could have occurred. However, detailed analysis of glycerophospholipid composition by LC-MS showed that there were no changes in headgroup composition of or the total amount of glycerophospholipids after 3 days of ISP-1 treatment in Neuro-2a or BHK/MRP1 cells or in lipid rafts derived from Neuro-2a cells. We did observe several changes in the fatty acid profile of glycerophospholipids in both Neuro-2a and BHK/MRP1 cells. Most of these changes appeared to be decreases of specific glycerophospholipid species with no clear similarity between the two cell types. These are not likely to be compensatory for the loss of sphingolipids in lipid rafts. In fact, detergent-free lipid rafts derived from Neuro-2a cells displayed a reduction of several PA species, which was hardly observed in whole cells. More interestingly as a potential compensatory mechanism, detergent-free lipid rafts displayed a highly significant relative increase in $\mathrm{PC}(32: 0)$. This represents $\mathrm{PC}$ species with $\mathrm{C} 16: 0$ fatty acids or a combination of C14:0 and C18:0 fatty acids. Thus, saturated but short instead of long-chain fatty acids in glycerophospholipids are favored and this suggests matching with the fatty acid composition of sphingolipids. The latter is skewed towards C16:0 in control conditions and even much more in the residual sphingolipid pool in ISP-1 treated cells.

One of the best characterized MDR mechanisms is the overexpression of energydependent drug efflux proteins of the $\mathrm{ABC}$ transporter protein super family, which prevent intracellular drug accumulation. Pgp (or ABCB1) and MRP1 (or ABCC1) are the most widely studied among these proteins. Both $\mathrm{ABC}$ transporters are known to depend on their direct lipid environment for optimal functioning [36-38]. Lavie et al. [9] were the first to show the association of an $\mathrm{ABC}$ transporter with a membrane domain in intact cells. They found that a substantial fraction of Pgp was located in Cav-1 containing Triton X-100-based DRMs in Pgp overexpressing cells. On the other hand, it was shown that Pgp and MRP1 were not associated with caveolae in two human MDR tumor cell lines [11]. Both MRP1 in HT29 $9^{\mathrm{col}}$ MDR tumor cells and Pgp in 2780AD MDR tumor cells were found to be enriched in membrane domains defined by their insolubility in the non-ionic detergent Lubrol. It was previously shown that inhibition of GCS and hence depletion of glycosphingolipids did not affect MRP1 efflux activity in HT29 $9^{\text {col }}$ cells [39] or in human neuroblastoma cells [18]. As noted above, other sphingolipids, most likely SM and Cer, can compensate for the loss of glycosphingolipids under the conditions of GCS inhibition. Here we show for the first time that extensive depletion of all sphingolipid classes, including Cer and SM, does not affect MRP1 efflux activity.

These results are in line with a recent analysis of the lipid composition of Lubrol- and Triton X-100-based DRMs. Sphingolipids were less enriched in Lubrol-based DRMs compared to Triton X-100-based DRMs. Instead, Lubrol-based DRMs contained relatively large amounts of the phospholipids PE and PS [40]. A layered raft model was proposed in which Lubrol-based DRMs consist of a highly sphingolipid-enriched Triton X-100 insoluble 
core, surrounded by a Triton X-100 soluble region, which contains relatively high levels of cholesterol and specific aminophospholipids and harbors most of the DRM-associated ABC transporter molecules [41,42]. Thus, sphingolipids are more enriched in ABC transporter-poor subdomains of DRMs and hence do not impact on ABC transporter function. A similar situation may occur for detergent-free lipid rafts, which are likely to consist of a larger membrane area than Triton X-100-based DRMs. According to the same model, detergent-free lipid rafts also have this Triton X-100 insoluble core [41,42].

In conclusion, we show that highly efficient depletion of sphingolipids does not abrogate the ability to isolate DRMs or detergent-free lipid rafts from cells. DRM and lipid raft fractions showed similar protein, cholesterol and phospholipid profiles in sphingolipiddepleted and control cells, while the gradient distributions of classical lipid raft markers were indistinguishable between the two. The fatty acid profile of the remaining sphingolipids as well as that of the glycerophospholipid PC shows an increase of highly saturated C16 species in detergent-free lipid rafts, while the glycerophospholipid headgroup composition is unchanged. Moreover, lipid raft localization as well as efflux function of the ABC transporter MRP1 were not affected by sphingolipid depletion. This uncouples MRP1 function not only from glycosphingolipids, but from all sphingolipid species. 


\section{References}

1. Pike, L.J. (2003) Lipid rafts: bringing order to chaos. J. Lipid Res. 44, 655-667

2. Brown, D. A. and London, E. (2000) Structure and function of sphingolipid- and cholesterol-rich membrane rafts. J. Biol. Chem. 275, 17221-17224

3. Brown, D.A. (2002) Structure and function of membrane rafts. Int. J. Med. Microbiol. 291, 433-437

4. Pike, L.J. (2004) Lipid rafts: heterogeneity on the high seas. Biochem. J. 378, 281-292

5. London, E. and Brown, D.A.. (2000) Insolubility of lipids in triton X-100: physical origin and relationship to sphingolipid/cholesterol membrane domains (rafts). Biochim. Biophys. Acta 1508, 182-195

6. Schuck, S., Honsho, M., Ekroos, K., Shevchenko, A. and Simons, K. (2003) Resistance of cell membranes to different detergents. Proc. Natl. Acad. Sci. U S A 100, 5795-5800

7. Macdonald, J.L. and Pike, L.J. (2005) A simplified method for the preparation of detergentfree lipid rafts. J. Lipid. Res. 46, 1061-1067

8. Pike, L. (2006) Rafts defined: A report on the Keystone symposium on lipid rafts and cell function. J. Lipid Res. 47, 1597-1598

9. Lavie, Y., Fiucci, G. and Liscovitch, M. (1998) Up-regulation of caveolae and caveolar constituents in multidrug-resistant cancer cells. J. Biol. Chem. 273, 32380-32383

10. Demeule, M., Jodoin, J., Gingras, D. and Béliveau, R. (2000) P-glycoprotein is localized in caveolae in resistant cells and in brain capillaries. FEBS Lett. 466, 219-224

11. Hinrichs, J.W.J., Klappe, K., Hummel, I. and Kok, J.W. (2004) ATP-binding cassette transporters are enriched in non-caveolar detergent-insoluble glycosphingolipid-enriched membrane domains (DIGs) in human multidrug-resistant cancer cells. J. Biol. Chem. 279, 5734-5738

12. Radeva, G., Perabo, J. and Sharom, F.J. (2005) P-glycoprotein is localized in intermediate-density membrane microdomains distinct from classical lipid rafts and caveolar domains. FEBS J. 272, 4924-4937

13. Eckford, P.D. and Sharom, F.J. (2008) Interaction of the P-glycoprotein multidrug efflux pump with cholesterol: effects on ATPase activity, drug binding and transport. Biochemistry 47, 13686-13698

14. Troost, J., Lindenmaier, H., Haefeli, W.E. and Weiss, J. (2004) Modulation of cellular cholesterol alters P-glycoprotein activity in multidrug-resistant cells. Mol. Pharmacol. 66, 1332-1339

15. Bleicher, R.J. and Cabot, M.C. (2002) Glucosylceramide synthase and apoptosis. Biochim. Biophys. Acta 1585, 172-178

16. Sietsma, H., Veldman, R.J. and Kok, J.W. (2001) The involvement of sphingolipids in multidrug resistance. J. Membrane Biol. 181, 153-162

17. Plo, I., Lehne, G., Beckstrom, K.J., Maestre, N., Bettaieb, A., Laurent, G. and Lautier, D.

(2002) Influence of ceramide metabolism on P-glycoprotein function in immature acute myeloid leukemia KG1a cells. Mol. Pharmacol. 62, 304-312

18. Dijkhuis, A.J., Klappe, K., Kamps, W., Sietsma, H. and Kok, J.W. (2006) Gangliosides do not affect $\mathrm{ABC}$ transporter function in human neuroblastoma cells. J. Lipid Res. 47, 11871194

19. Brown, D.A. (2006) Lipid rafts, detergent-resistant membranes, and raft targeting signals. Physiol. 21, 430-439

20. Fridberg, A., Olsen, C.L., Nakayasu, E.S., Tyler, K.M., Almeida, L.C. and Engman, D.M. (2008) Sphingolipid synthesis is necessary for kinetoplast segregation and cytokinesis in Trypanosoma brucei. J. Cell Sci. 121, 522-535

21. Chang, X., Hou, Y. and Riordan, R.J. (1997) ATPase activity of purified multidrug resistance-associated protein. J. Biol. Chem. 272, 30962-30968 
22. Lisanti, M. P., Tang, Z., Scherer, P.E. and Sargiacomo, M. (1995) Caveolae purification and glycosylphosphatidylinositol-linked protein sorting in polarized epithelia. Methods Enzymol. 250, 655-668

23. Smith, P.K., Krohn, R.I., Hermanson, G.T., Mallia, A.K., Gartner, F.H., Provenzano, M.D., Fujimoto, E.K., Goeke, N.M., Olson, B.J. and Klenk, D.C. (1985) Measurement of protein using bicinchoninic acid. Anal. Chem. 150, 76-85

24. Peterson, G.L. (1977) A simplification of the protein assay method of Lowry et al. which is more generally applicable. Anal. Biochem. 83, 346-356

25. Bligh, E.G. and Dyer, W.J. (1959) A rapid method of total lipid extraction and purification. Can. J. Biochem. Physiol. 37, 911-917

26. Gamble, W., Vaughan, M., Kruth, H.S. and Avignan, J. (1978) Procedure for determination of free and total cholesterol in micro- or nanogram amounts suitable for studies with cultured cells. J. Lipid Res. 19, 1068-1070

27. Böttcher, C.J.F., van Gent, C.M. and Pries, C. (1961) A rapid and sensitive submicro phosphorus determination. Anal. Chim. Acta 24, 203-204

28. Carmichael, J., Degraff, W.G., Gazdar, A.F., Minna, J.D. and Mitchel, J.B. (1987) Evaluation of a tetrazolium-based semiautomated colorimetric assay: assessment of chemosensitivity testing. Cancer Res. 47, 936-942

29. Harder, T. and Simons, K. (1997) Caveolae, DIGs, and the dynamics of sphingolipidcholesterol microdomains. Curr. Opin. Cell Biol. 9, 534-542

30. Simons, K. and Ikonen, I. (1997) Functional rafts in cell membranes. Nature 387, 569-572

31. Ostermeyer, A.G., Beckrich, B.T., Ivarson, K.A., Grove, K.E and Brown, D.A. (1999) Glycosphingolipids are not essential for formation of detergent-resistant membrane rafts in melanoma cells. J. Biol. Chem. 274, 34459-34466

32. Munro, S. (2003) Lipid rafts: Elusive or illusive. Cell 115, 377-388

33. Sengupta, P., Baird, B. and Holowka, D. (2007) Lipid rafts, fluid/fluid phase separation, and their relevance to plasma membrane structure and function. Semin. Cell Dev. Biol. 18, 583-590

34. Grzybek, M., Kozubek, A., Dubielecka, P. and Sikorski, F. (2005) Rafts - the current picture. Fol. Histochem. Cytobiol. 43, 3-10

35. Heerklotz, H. (2002) Triton promotes domain formation in lipid raft mixtures. Biophys. J. 83, 2693-2701

36. Dudeja, P. K., Anderson, K.M., Harris, J.S., Buckingham, L. and Coon, J.S. (1995) Reversal of multidrug resistance phenotype by surfactants: relationship to membrane lipid fluidity. Arch. Biochem. Biophys. 319, 309-315

37. Sinicrope, F.A., Dudeja, P.K., Bissonette, B.M., Safa, A.R. and Brasitus, T.A. (1992) Modulation of P-glycoprotein-mediated drug transport by alterations in lipid fluidity of rat liver canalicular membrane vesicles. J. Biol. Chem. 267, 24995-2500

38. Romsicki, Y and Sharom, F.J. (1999) The membrane lipid environment modulates drug interactions with the P-glycoprotein multidrug transporter. Biochemistry 38, 6887-6896

39. Klappe K., Hinrichs, J.W.J., Kroesen, B.J., Sietsma, H. and Kok, J.W. (2004) MRP1 and glucosylceramide are coordinately over expressed and enriched in rafts during multidrug resistance acquisition in colon cancer cells. Int. J. Cancer 110, 511-522

40. Hinrichs, J.W.J, Klappe, K., van Riezen, M. and Kok, J.W. (2005) Drug resistanceassociated changes in sphingolipids and $\mathrm{ABC}$ transporters occur in different regions of membrane domains. J. Lipid Res. 46, 2367-2376

41. Hinrichs, J.W.J., Klappe, K. and Kok, J.W. (2005) Rafts as missing link between multidrug resistance and sphingolipid metabolism. J. Membr. Biol. 203, 57-64

42. Klappe, K., Hummel, I., Hoekstra, D. and Kok, J.W. (2009) Lipid dependence of ABC transporter localization and function. Chem. Phys. Lipids 161, 57-64 


\section{Tables}

\begin{tabular}{|c|c|c|c|c|c|c|}
\hline & \multicolumn{2}{|c|}{$\begin{array}{l}\text { Neuro-2a } \\
\text { cells }\end{array}$} & \multicolumn{2}{|c|}{$\begin{array}{l}\text { Neuro-2a } \\
\text { lipid rafts }\end{array}$} & \multicolumn{2}{|c|}{$\begin{array}{c}\mathrm{BHK} / \mathrm{MRP} 1 \\
\text { cells }\end{array}$} \\
\hline & fold & $\mathrm{p}$ & fold & $\mathrm{p}$ & fold & $\mathrm{p}$ \\
\hline GlcCer C16:0 & 1.70 & $3.2 \mathrm{E}-04$ & 1.54 & $2.7 \mathrm{E}-02$ & 1.75 & $1.4 \mathrm{E}-05$ \\
\hline GlcCer C24:1 & 0.37 & 5.2E-03 & n.d. & & 0.38 & 8.2E-05 \\
\hline GlcCer C24:0 & 0.41 & $1.4 \mathrm{E}-03$ & n.d. & & 37 & $3.6 \mathrm{E}-04$ \\
\hline Cer C16:0 & 1.56 & $1.4 \mathrm{E}-03$ & 1.26 & $2.8 \mathrm{E}-01$ & 1.43 & $5.0 \mathrm{E}-03$ \\
\hline Cer C24:1 & 0.43 & $5.5 \mathrm{E}-03$ & 0.09 & $5.0 \mathrm{E}-04$ & 0.58 & $1.6 \mathrm{E}-03$ \\
\hline Cer C24:0 & 0.46 & $1.8 \mathrm{E}-03$ & 0.72 & $2.0 \mathrm{E}-01$ & 0.54 & $1.3 \mathrm{E}-02$ \\
\hline LacCer C16:0 & 1.42 & $1.6 \mathrm{E}-02$ & 1.06 & $6.3 \mathrm{E}-01$ & 1.20 & $8.2 \mathrm{E}-02$ \\
\hline LacCer C24:1 & 0.71 & $1.2 \mathrm{E}-03$ & 1.31 & $5.7 \mathrm{E}-02$ & 0.64 & 4.7E-03 \\
\hline LacCer C24:0 & 0.76 & $3.2 \mathrm{E}-02$ & 0.38 & $6.3 \mathrm{E}-02$ & 0.86 & $2.3 \mathrm{E}-01$ \\
\hline SM C16:0 & 1.13 & $6.6 \mathrm{E}-02$ & 1.15 & $3.9 \mathrm{E}-01$ & 1.08 & 2.7E-04 \\
\hline SM C24:1 & 0.44 & $4.0 \mathrm{E}-02$ & 0.37 & $9.1 \mathrm{E}-03$ & 0.43 & 4.2E-05 \\
\hline SM C24:0 & 1.95 & $9.5 \mathrm{E}-01$ & 0.12 & 8.2E-02 & 0.67 & 4.1E-04 \\
\hline
\end{tabular}

Table I. Fatty acid composition of sphingolipids from Neuro-2a or BHK/MRP1 cells or detergent-free lipid rafts derived from Neuro-2a cells after treatment with ISP-1

The effect of ISP-1 treatment (three days incubation with $0.5 \mu \mathrm{M}$ ) on the fatty acid profile of sphingolipids in Neuro-2a and BHK/MRP1cells as well as Neuro-2a derived detergent-free lipid rafts was established by LC-ESI-MS/MS. Fold indicates the ratio of the amount of a given sphingolipid in ISP-1 treated cells (or detergent-free lipid rafts) divided by the amount in control cells, a value of 1 indicating no effect of ISP-1 treatment. Data represent the mean of 3 independent experiments. Bold font style indicates values where ISP-1 and control are significantly $(\mathrm{P}<0.05)$ different as determined by Student's $t$-test. N.d. means not detectable under ISP-1 conditions. 


\section{Figure legends}

Figure 1. Sphingolipids are efficiently depleted by ISP-1 treatment in whole cells, DRMs and detergent-free lipid rafts

A. The effect of ISP- 1 treatment ( 3 days incubation with $0.5 \mu \mathrm{M}$ ) on sphingolipid levels in Neuro-2a cells was established by equilibrium radiolabeling. B. The effect of ISP-1 treatment ( 3 days incubation with $0.5 \mu \mathrm{M}$ ) on sphingolipid levels in Neuro-2a cells was established by LC-ESI-MS/MS. C. Sphingolipids of Neuro-2a-derived DRMs with equal protein content were extracted and analyzed by LC-ESI-MS/MS. D. Sphingolipids of Neuro-2a-derived detergent-free lipid raft fractions with equal protein content were extracted and analyzed by LC-ESI-MS/MS. E. The effect of ISP-1 treatment ( 3 days incubation with $0.5 \mu \mathrm{M}$ ) on sphingolipid levels in BHK/MRP1 cells was established by LC-ESI-MS/MS. Values of each lipid as well as the sum of all lipids are expressed as a percentage of those from untreated cells $(100 \%)$. Data represent the mean + SD of 3 independent experiments.

\section{Figure 2. Ganglioside depletion by ISP-1 treatment}

Mass analysis of GM3, the only ganglioside present in Neuro-2a cells, shows that this ganglioside is undetectable and thus strongly reduced in ISP-1 treated cells (lane 4) compared to control cells (lane 3), which present as a characteristic double band. A ganglioside mixture (lane 1) and GM3 (lane 2) were applied as references.

Figure 3. ISP-1 treatment does not affect DRM marker distribution in Lubrol-based gradients of Neuro-2a cells

A. After ISP-1 treatment, Lubrol-based DRMs were isolated from Neuro-2a cells and analyzed for Src, Cav-1, flotillin, and MRP1 distribution along the gradient. Gradient samples were applied on SDS-PAGE based on equal volume. DRM fractions are indicated. The figure shows a typical example out of 3 independent experiments. B. The relative amount of a specific protein found in the lipid raft fractions of this typical experiment is quantified. Control: open bars; ISP-1: closed bars.

Figure 4. ISP-1 treatment does not affect protein, cholesterol and phopholipid profile in detergent-free lipid raft gradients of Neuro-2 a cells

A,B. Detergent-free lipid raft gradients were analyzed for cholesterol (A) and sphingolipid (B) profile. These lipid classes were measured in pooled gradient fractions and are expressed relative to protein content of the pooled gradient fractions. To calculate the ratio cholesterol/protein and sphingolipid/protein, the values of $\%$ in the gradient of each, cholesterol, sphingolipids and protein, were used. This ratio is therefore without unit and represents the relative enrichment in gradient fractions of cholesterol and sphingolipids, respectively, relative to protein enrichment in the respective fractions. Data represent the mean + SD of 3 independent experiments. *Values are significantly $(\mathrm{P}<0.05)$ different from those of fractions 5-6 (non-lipid raft membrane fractions) as determined by Student's $t$-test. C-E. After ISP-1 treatment, detergent-free lipid rafts were isolated from Neuro-2a cells and analyzed for protein (C), cholesterol (D) and phospholipid (E) profile. Lipid raft fractions are indicated. Control. open bars; ISP-1: closed bars. Data represent the mean + SD of 3 independent experiments. There are no significant $(\mathrm{P}<0.05)$ differences between ISP-1 treated and control cells as determined by Student's $t$-test.

Figure 5. ISP-1 treatment does not affect lipid raft marker distribution in detergent-free lipid raft gradients of Neuro-2a and BHK/MRP1 cells

A. After ISP-1 treatment, detergent-free lipid rafts were isolated from Neuro-2a cells and analyzed for Src, Cav-1, flotillin, and MRP1 distribution along the gradient. Gradient samples 
were applied on SDS-PAGE based on equal volume. Lipid raft fractions are indicated. A typical example out of three independent experiments is shown. B. The relative amount of a specific protein found in the lipid raft fractions is quantified. Data represent the mean $+\mathrm{SD}$ of 3 independent experiments. There are no significant $(\mathrm{P}<0.05)$ differences between ISP-1 treated (closed bars) and control cells (open bars) as determined by Student's $t$-test. C. After ISP-1 treatment, detergent-free lipid rafts were isolated from BHK/MRP1 cells and analyzed for Src, Cav-1, and MRP1 distribution along the gradient. Gradient samples were applied on SDS-PAGE based on equal volume. Lipid raft fractions are indicated.

Figure 6. ISP-1 treatment does not affect the amount or headgroup composition of glycerophospholipids or the amount of cholesterol

A-C. The effect of ISP-1 treatment (3 days incubation with $0.5 \mu \mathrm{M}$ ) on glycerophospholipid levels in Neuro-2a cells (A), Neuro-2a derived detergent-free lipid rafts (B) and BHK/MRP1 cells (C) was established by LC-MS.

D,E. The effect of ISP-1 treatment ( 3 days incubation with $0.5 \mu \mathrm{M}$ ) on cholesterol content of Neuro-2a cells (D) and Neuro-2a-derived detergent-free lipid rafts (E) was analyzed with a cholesterol assay.

F-H. The effect of ISP-1 treatment ( 3 days incubation with $0.5 \mu \mathrm{M}$ ) on glycerophospholipid headgroup composition in Neuro-2a cells (F), Neuro-2a derived detergent-free lipid rafts (G) and BHK/MRP1 cells (H) was established by LC-MS. Control: open bars; ISP-1: closed bars. Data represent the mean $+\mathrm{SD}$ of 3 independent experiments. There are no significant $(\mathrm{P}<$ $0.05)$ differences between ISP-1 treated and control cells as determined by Student's $t$-test.

Figure 7. Fatty acid composition in sphingolipids of Neuro-2a cells The fatty acid profile of sphingolipids in Neuro-2a cells was analyzed by LC-ESI-MS/MS. Data represent the mean + SD of 3 independent experiments.

Figure 8. ISP-1 treatment does not affect MRP1-mediated efflux activity of Neuro-2a or BHK/MRP1 cells

A,B. After ISP-1 treatment, Neuro-2a (A) or BHK/MRP1 cells (B) were loaded with CFDA $(0.5 \mu \mathrm{M})$. Retention of fluorescence was determined by cytometric analysis at several timepoints after cells were placed at $37^{\circ} \mathrm{C}$ and is expressed as \% of the 0 min value. Control: open squares; ISP-1: closed squares. MK571 $(20 \mu \mathrm{M})$ was used as a positive control for MRP1 efflux inhibition. Control + MK571: open triangle; ISP-1 + MK571: closed triangle. Data represent the mean $\pm \mathrm{SD}$ of 3 independent experiments. There are no significant $(\mathrm{P}<0.05)$ differences between ISP-1 treated and control cells as determined by Student's $t$-test. 

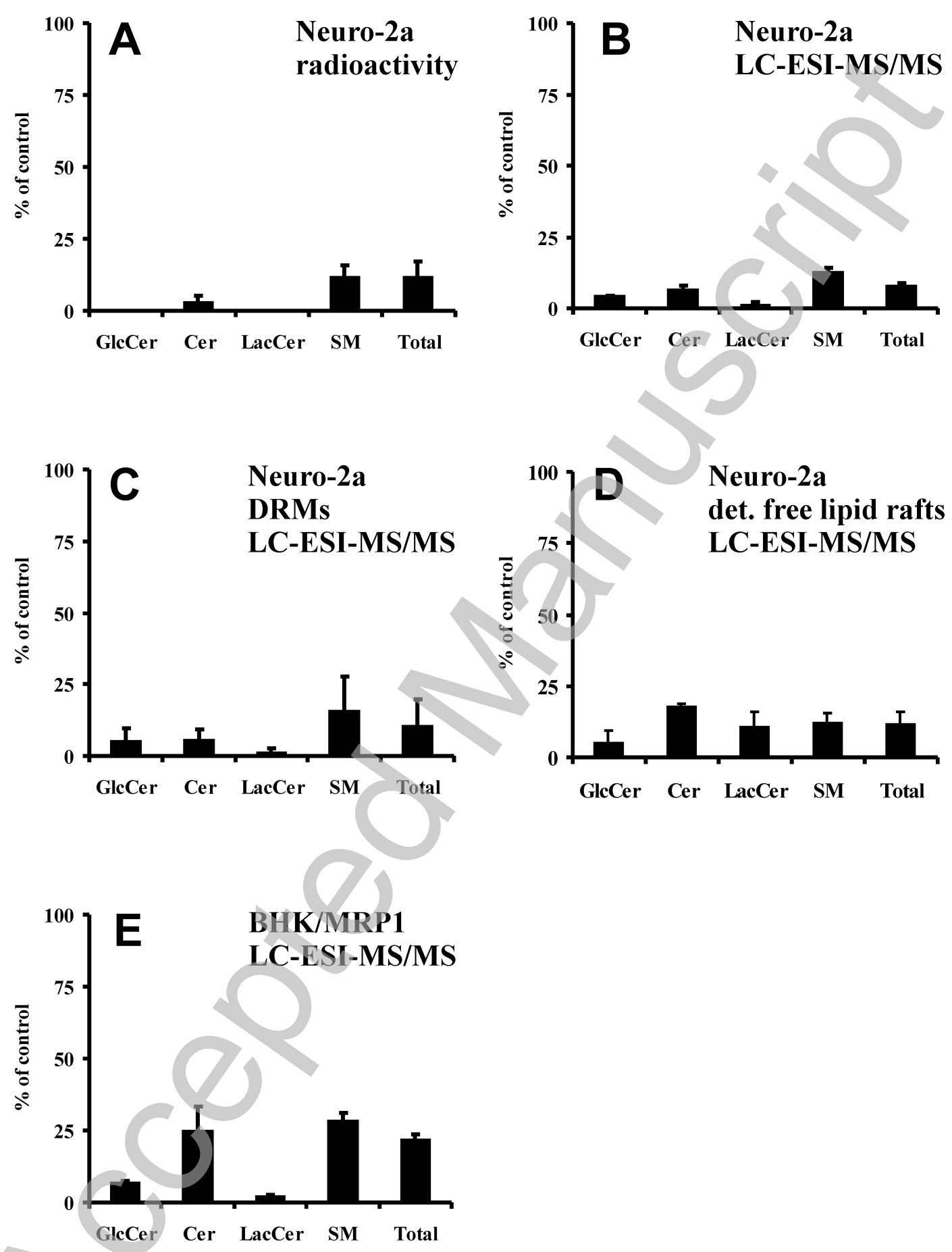

Figure 1 
B Biochemical Journal Immediate Publication. Published on 06 Jul 2010 as manuscript BJ20091882

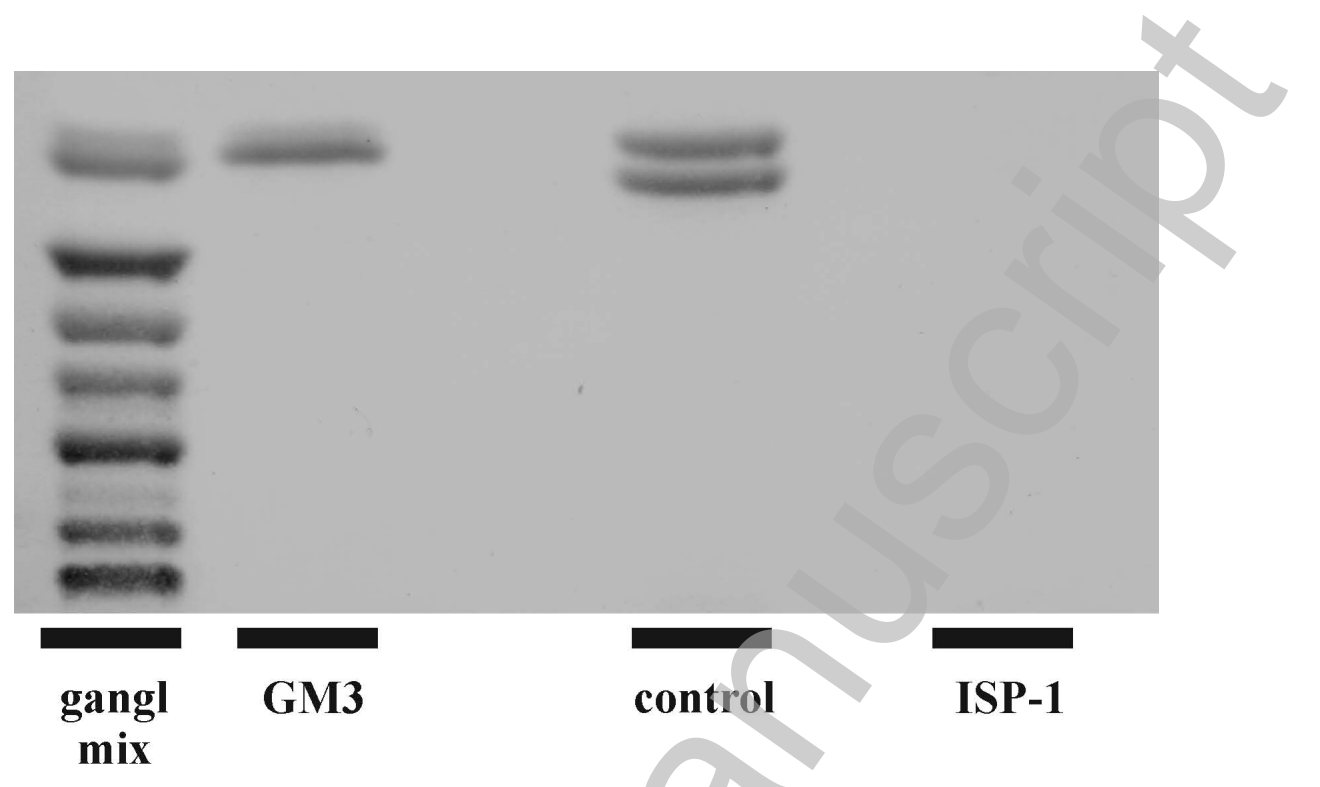

Figure 2

Licenced copy. Copying is not permitted, except with prior permission and as allowed by law. (c) 2010 The Authors Journal compilation ( 2010 Portland Press Limited 
A

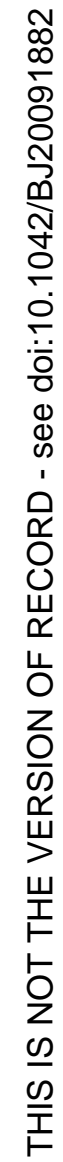

\section{Control}

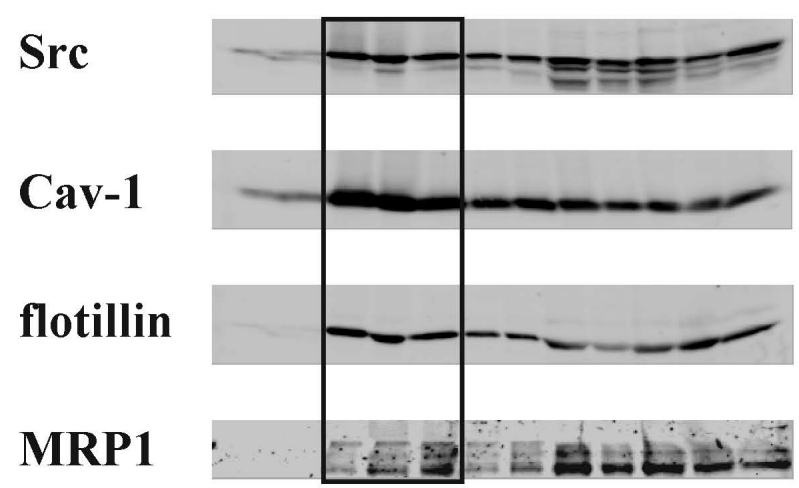

DRM fractions
ISP-1

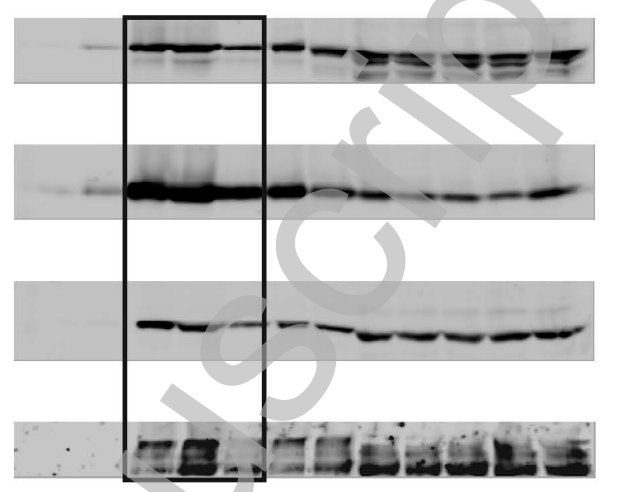

DRM fractions

B

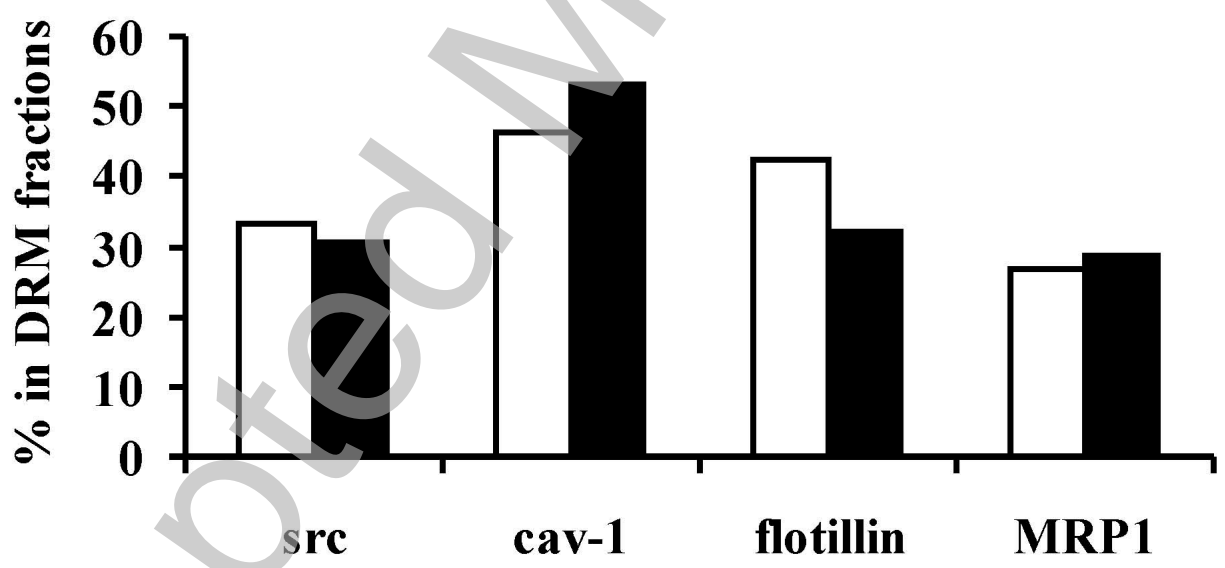

Figure 3 
A

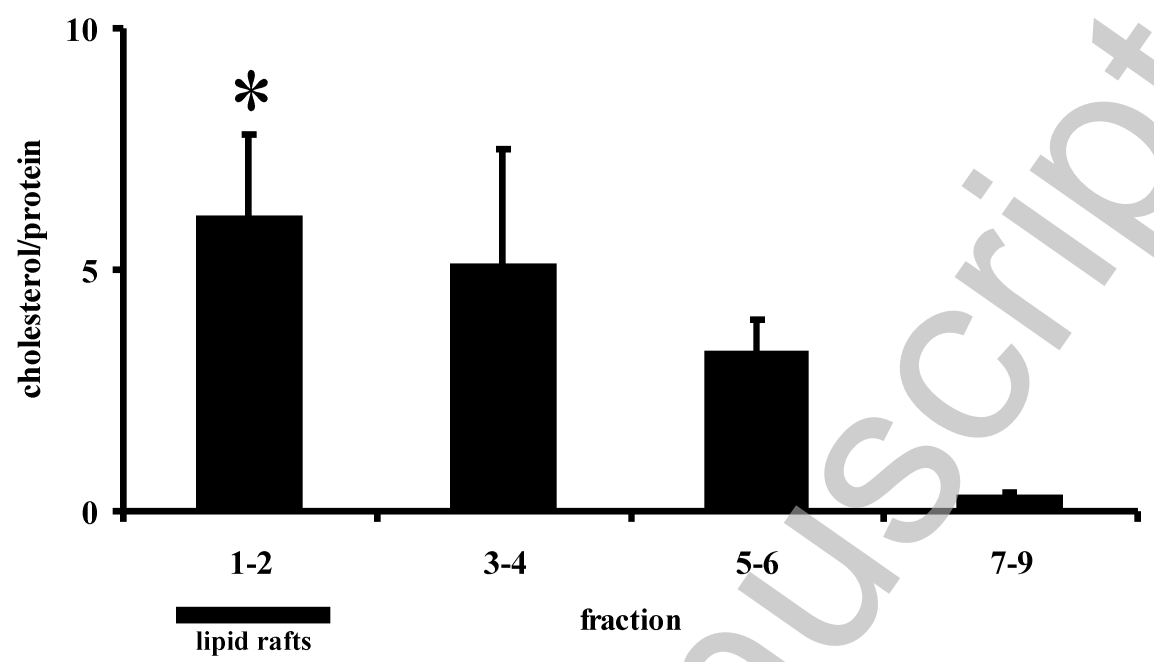

B

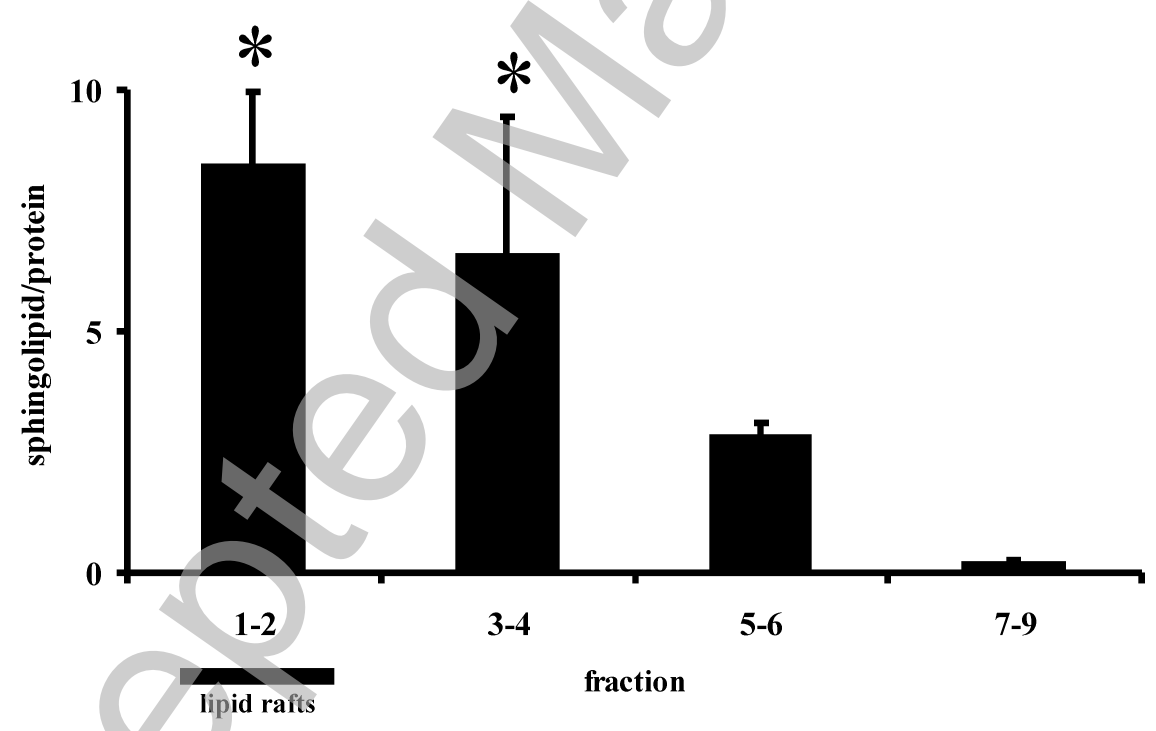

Figure 4AB 
C

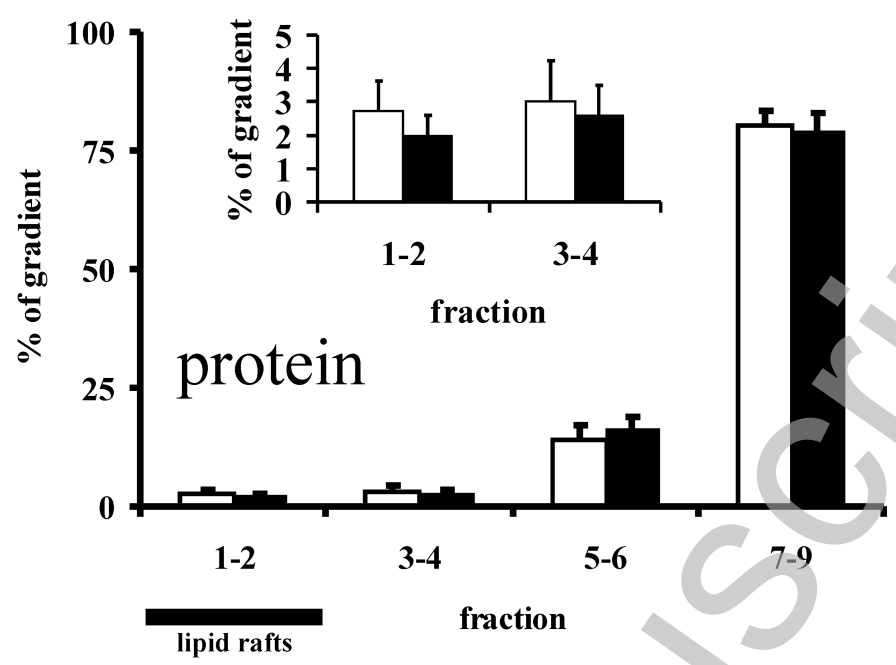

D

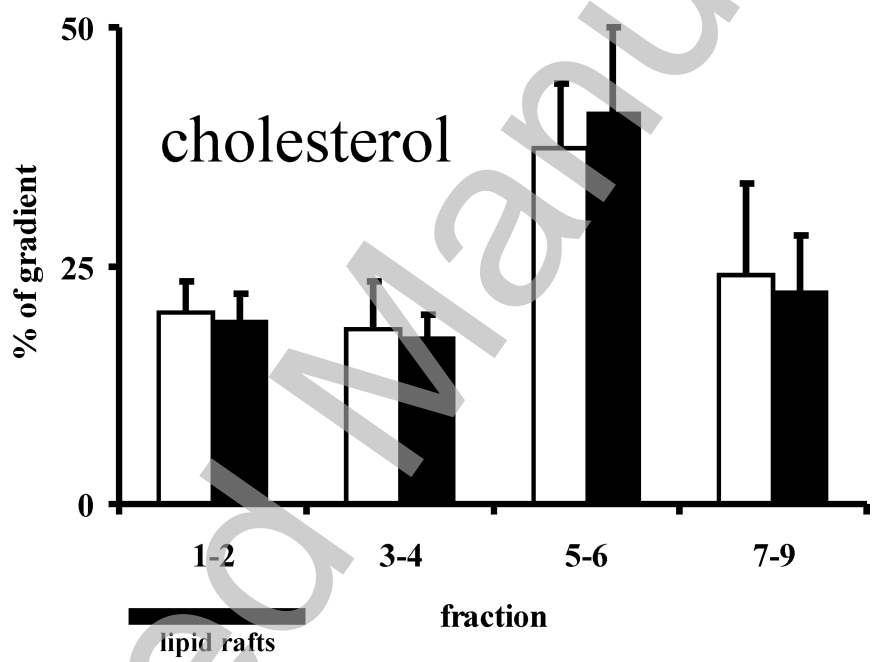

E

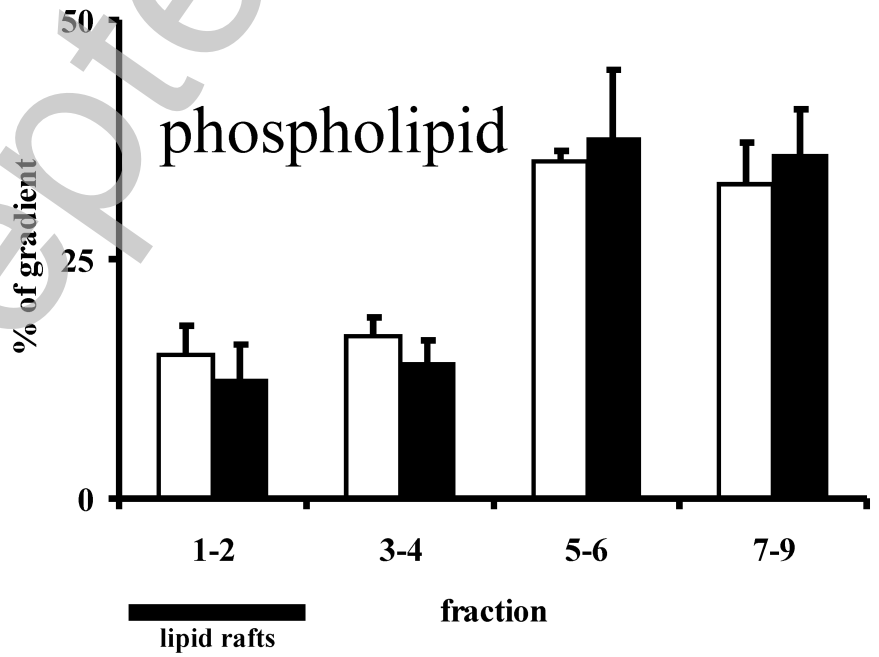

Figure 4CDE 


\section{Neuro-2a}

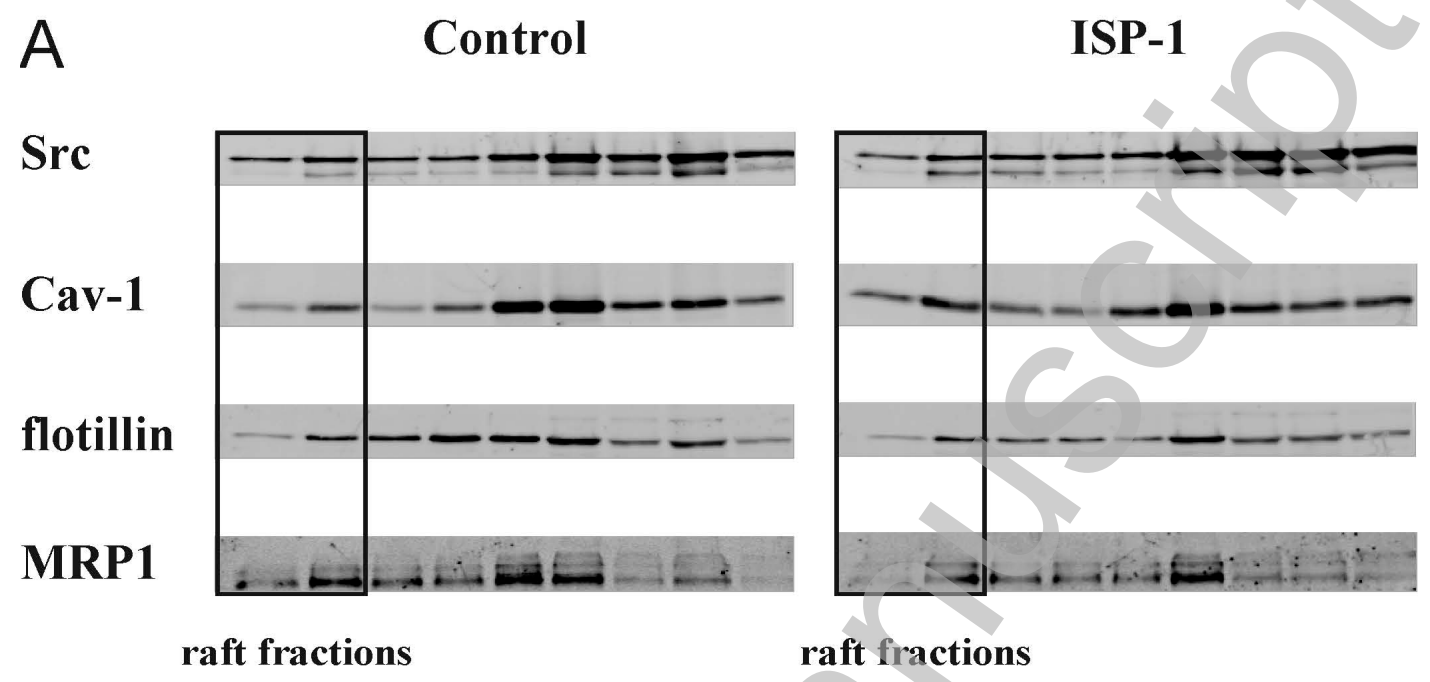

B

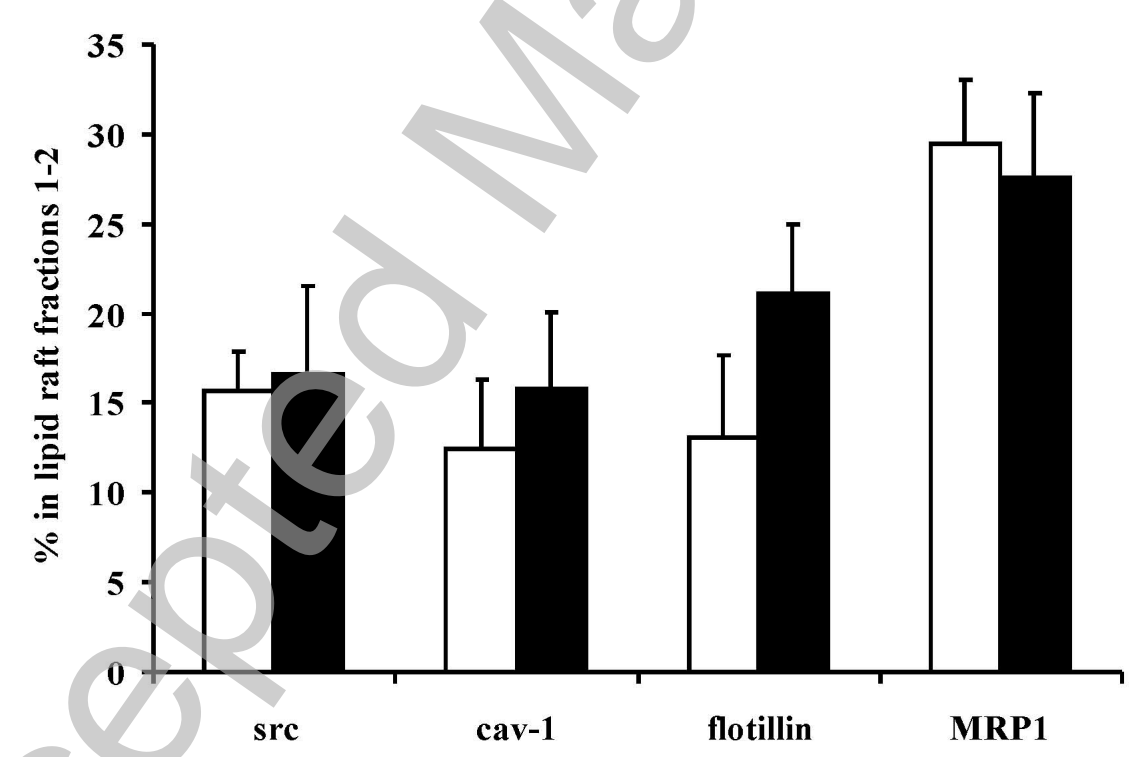

Figure 5AB 


\section{BHK/MRP1}

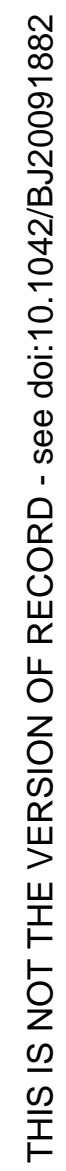

C

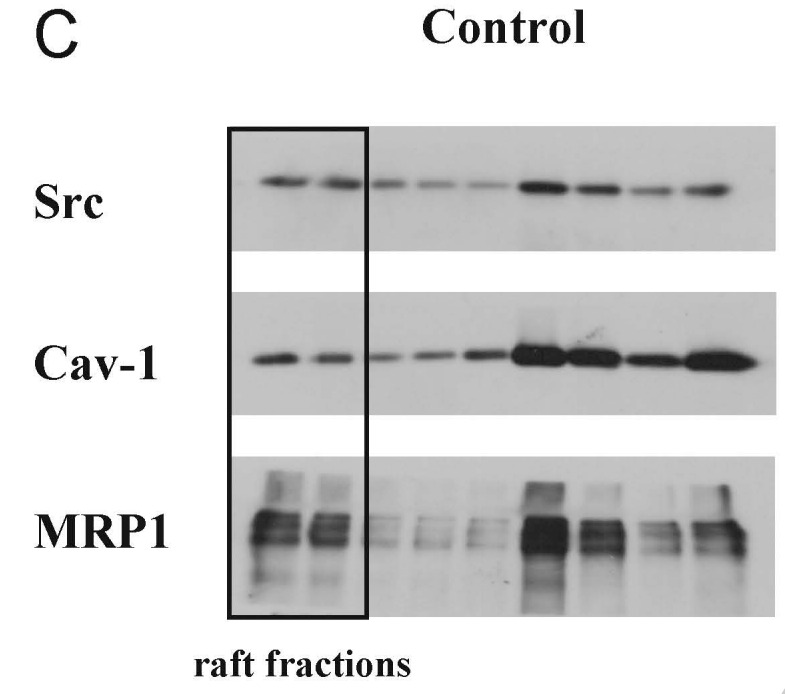

ISP-1

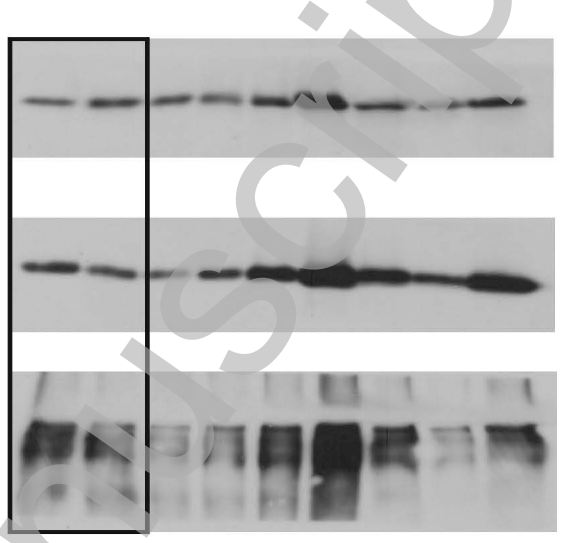

raft fractions

\section{Figure 5C}


A

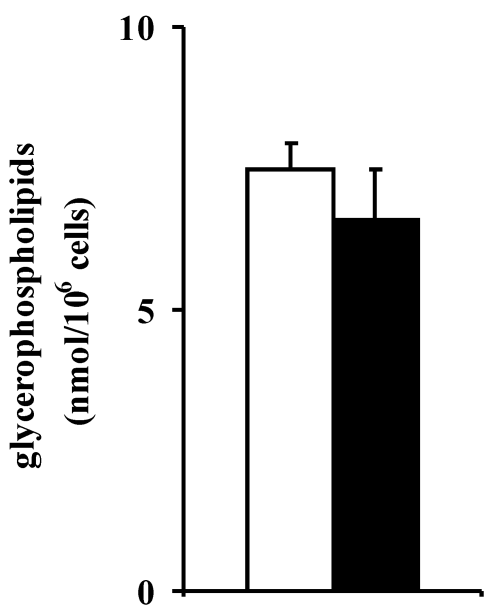

Neuro-2a

C

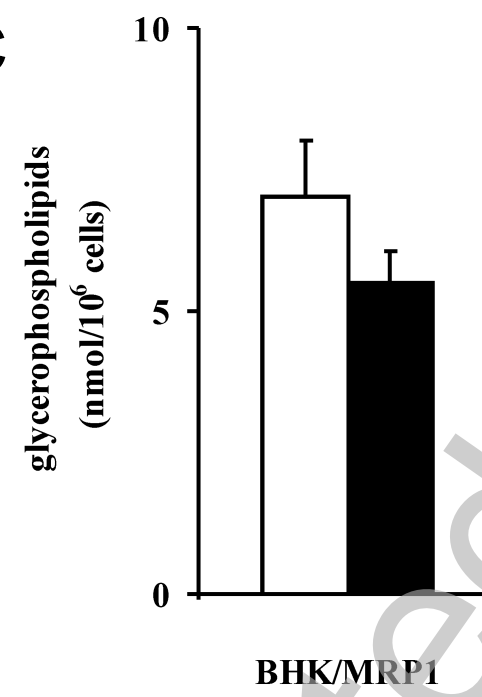

$\mathrm{D}$

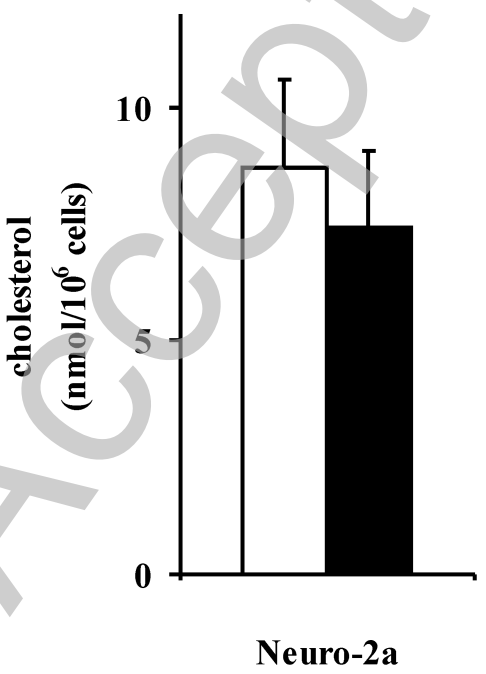

B

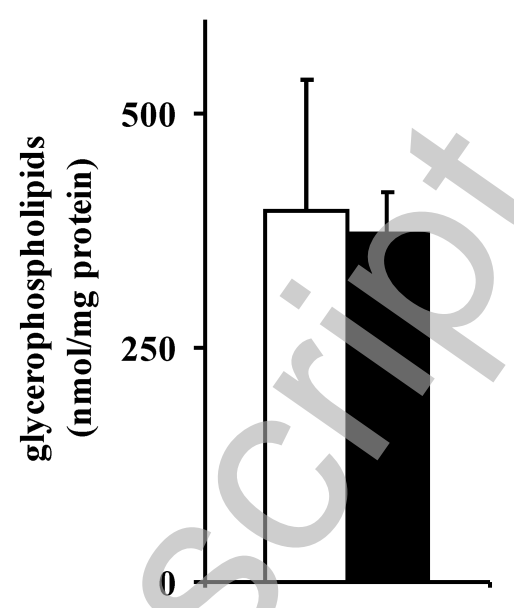

Neuro-2a lipid rafts
$E$

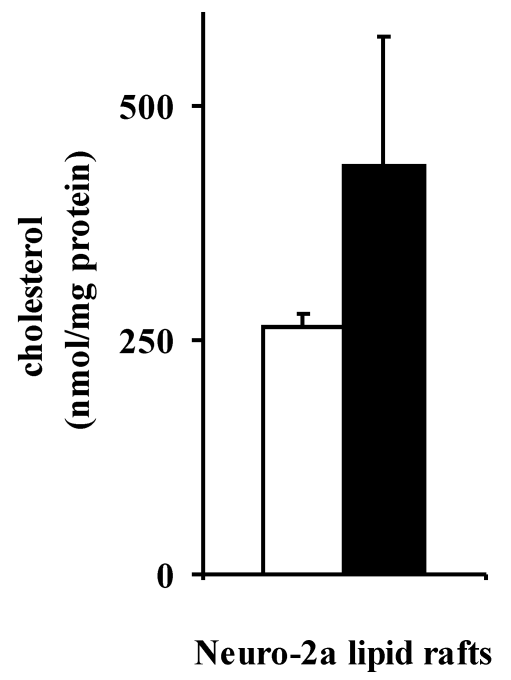


$\mathrm{F}$

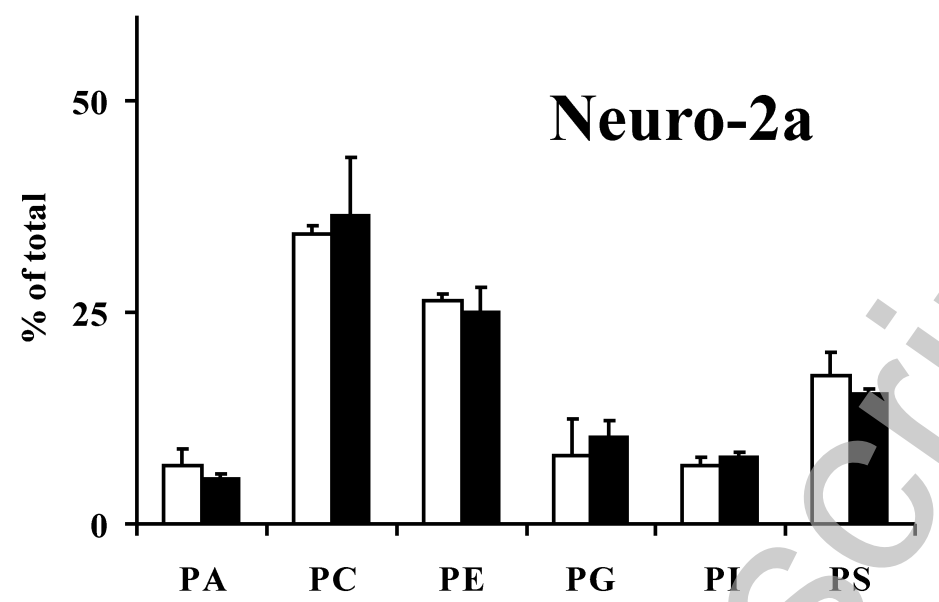

G

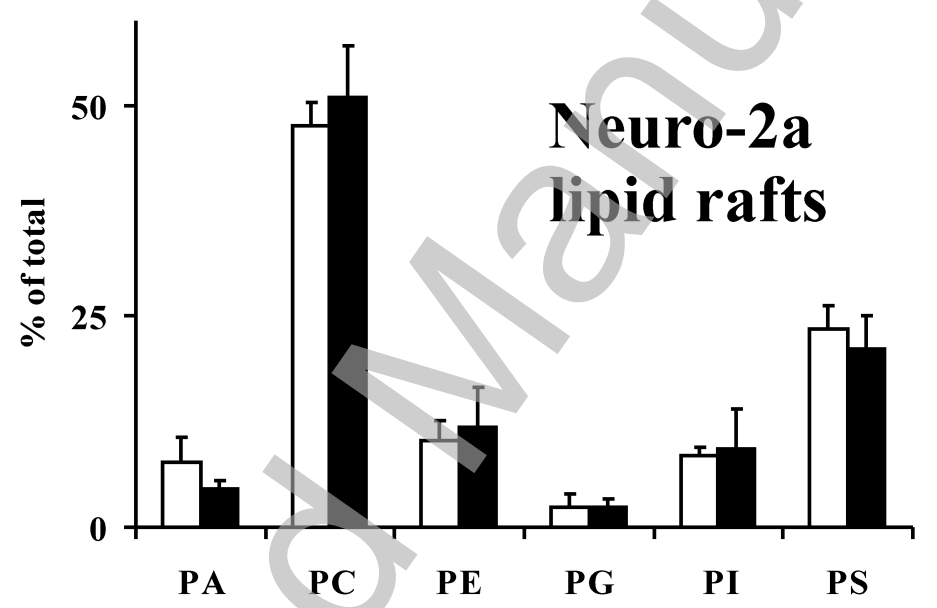

$\mathrm{H}$

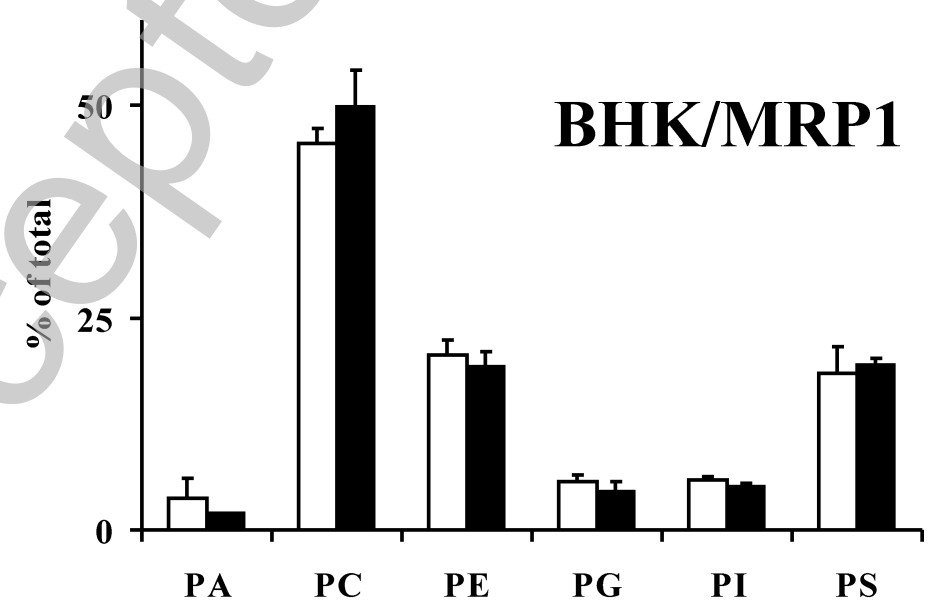

Figure 6FGH 
B Biochemical Journal Immediate Publication. Published on 06 Jul 2010 as manuscript BJ20091882

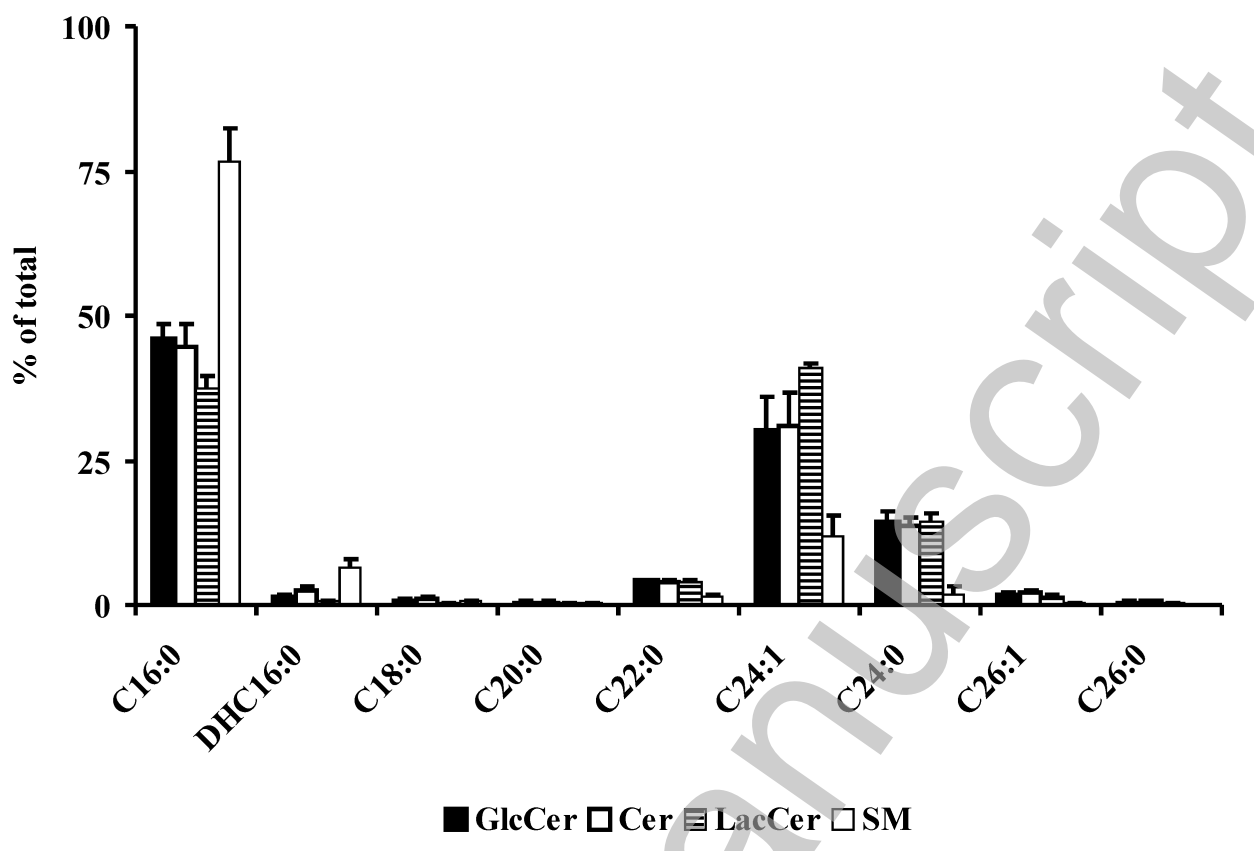

Figure 7 
A

Neuro-2a

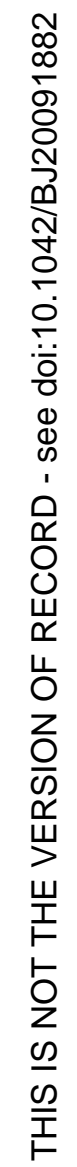

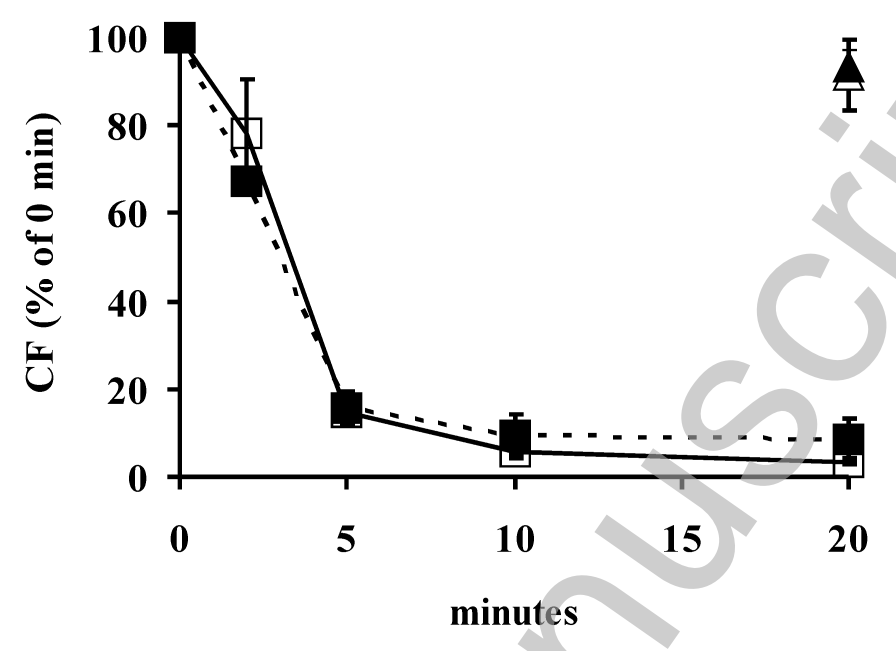

B BHK/MRP1

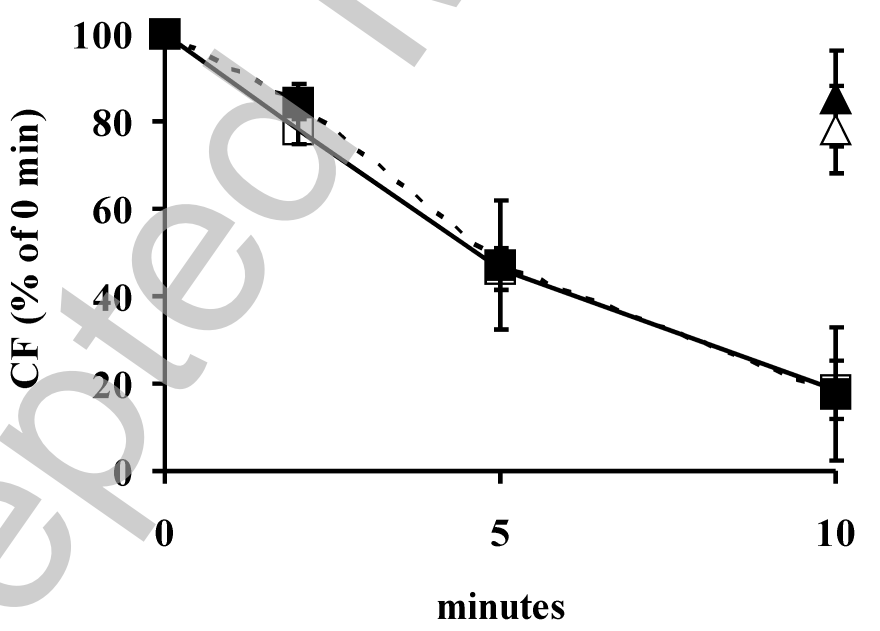

Figure 8 